\title{
Spatiotemporal Decompositions of Summer Drought in China and Its Teleconnection with Global Sea Surface Temperatures during 1901-2012 0
}

\author{
YAXIN ZHANG \\ College of Urban and Environmental Sciences, and Key Laboratory for Earth Surface Processes of Ministry of Education, \\ Peking University, Beijing, China \\ MENGXI Wu \\ Department of Earth, Environmental and Planetary Sciences, Brown University, Providence, Rhode Island

\section{DELONG LI} \\ College of Urban and Environmental Sciences, and Key Laboratory for Earth Surface Processes of Ministry of Education, \\ Peking University, Beijing, China \\ YONGGANG LIU \\ College of Physics, Peking University, Beijing, China

\section{SHUANGCHENG LI} \\ College of Urban and Environmental Sciences, and Key Laboratory for Earth Surface Processes of Ministry of Education, \\ Peking University, Beijing, China
}

(Manuscript received 24 May 2016, in final form 4 May 2017)

\begin{abstract}
The teleconnection between the summer (June-August) Palmer drought severity index (PDSI) in China and seasonal global sea surface temperatures (SSTs) is investigated at both spatial and temporal scales during 1901-2012. Three pairs of coupled spatial patterns for China's PDSI and global SST anomalies are identified using the singular value decomposition (SVD) method. With a combination of ensemble empirical mode decomposition (EEMD) and multiple linear regression (MLR) analysis, it is found that the first mode, the sea ice loss-global warming pattern, causes wetness over north and northeastern China and drying over Inner Mongolia. The North Pacific Current (NPC) mode shows that a warmer NPC corresponds to a wetter summer over eastern China and a drier one over the Tibetan Plateau. Both NPC and Pacific decadal oscillation (PDO) affect moisture variability in northern China and over the Tibetan Plateau, with the NPC mode more important in the centennial scale, while the PDO mode is more important in the multidecadal scale.
\end{abstract}

\section{Introduction}

Drought is defined as "a prolonged absence or marked deficiency of precipitation," "a deficiency of precipitation that results in water shortage for some activity or for some group," or "a period of abnormally

Supplemental information related to this paper is available at the Journals Online website: http://dx.doi.org/10.1175/ JCLI-D-16-0405.s1.

Corresponding author: Shuangcheng Li, scli@urban.pku.edu.cn dry weather sufficiently prolonged for the lack of precipitation to cause a serious hydrological imbalance" (IPCC 2007). Drought is one of the most deadly natural threats to mankind. The population killed or otherwise affected by droughts from 1967 to 1991 outstrips the total number of victims of all other meteorological disasters (Obasi 1994).

China frequently suffers severe drought disaster. During recent decades, large-scale droughts have gradually become a nationwide concern, with the annual drought area rapidly increasing from $5.18 \times 10^{6}$ ha in the 1950 s to $15.37 \times 10^{6}$ ha in the 2000s (Fig. 1). Extended 

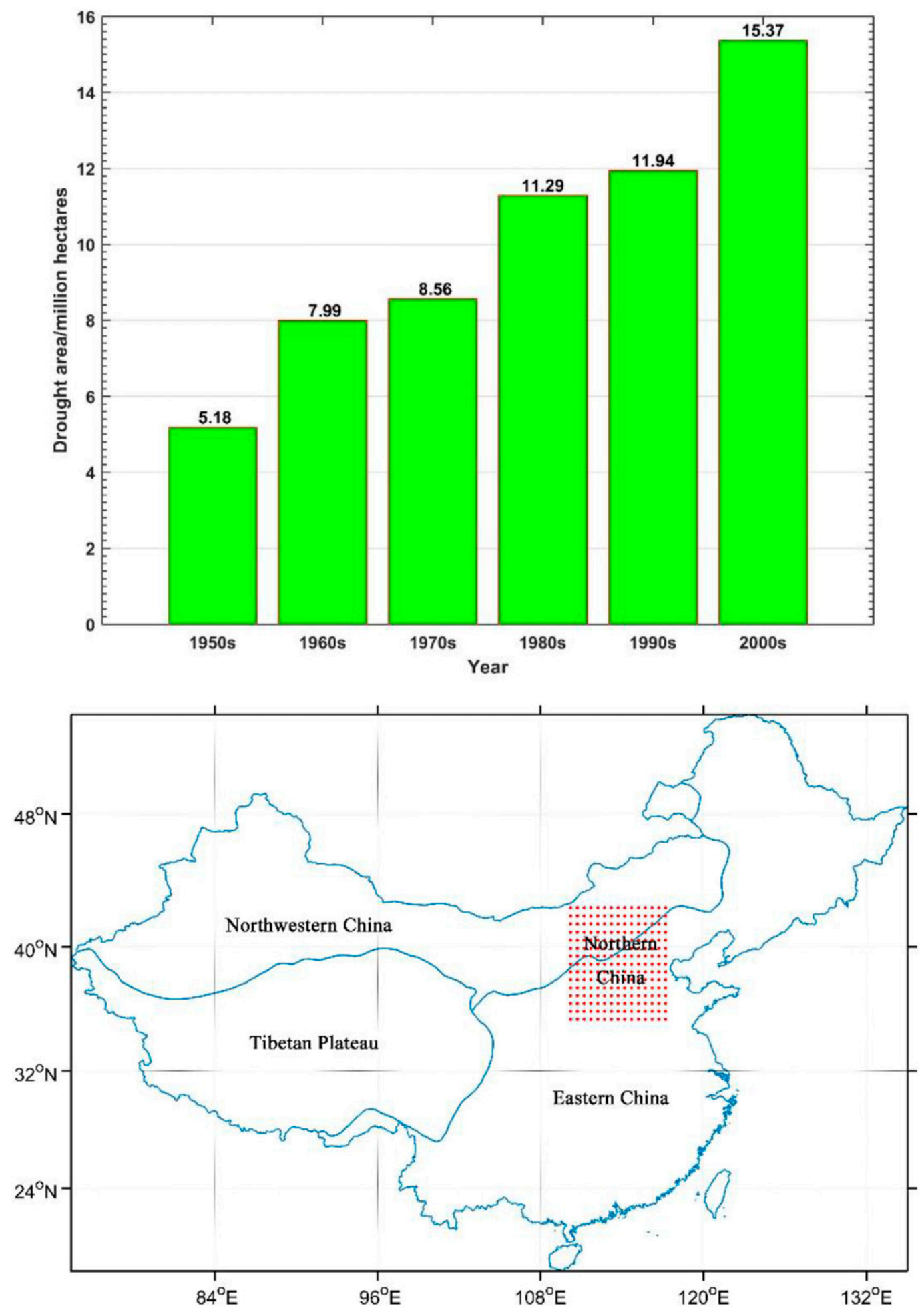

FIG. 1. (top) Average annual drought area in China in past decades. Data from 1950s to 1990s are cited from Yu (2007), and average annual drought area in 2000s was calculated from annual drought area archived by the National Bureau of Statistics of China (available online at http://data.stats.gov.cn/english/). (bottom) Location of northern China (red stippling; $35^{\circ}-42.5^{\circ} \mathrm{N}, 110^{\circ}-117.5^{\circ} \mathrm{E}$ ) and the geographic regionalization suggested by Zhao (1983). 
droughts can impact both natural and economic environments in China, especially in its southern area where droughts have recurred at short intervals in the last decade (Qiu 2010). Two waves of drought in 2005 and 2008 severely affected Yunnan Province and other parts of southwestern China. In 2004 and 2007, Sichuan and Hunan Provinces also experienced serious droughts, which resulted in depletion of freshwater resources. A 4-yr drought from 2009 to 2012 led to tremendous losses in agriculture and aquaculture in southern China. Because droughts can cause enormous economic losses, it is of vital importance to identify the drivers of the country's drought and develop a forecast scheme.

A variety of indices have been introduced to measure the severity of drought, each with its unique advantages and shortcomings (Heim 2002; Mu et al. 2013; Dai 2011a). Among the diverse measures of drought, the self-calibrated Palmer drought severity index (PDSI), a locally standardized index, is appropriate for research at the national scale (Shabbar and Skinner 2004).

Regional water balance depends on atmospheric circulations, which teleconnect to global oceanic processes. Accordingly, an understanding of the relationships between the intensity, variability, and spatial distribution of droughts and large-scale ocean-atmosphere forcing is essential for predicting seasonal droughts. A few international studies have looked into associations between droughts and sea surface temperatures (SSTs). Rajagopalan et al. (2000) identified coupled patterns of drought over the continental United States and global SST over the past century. Shabbar and Skinner (2004) related summer drought in Canada to previous winter SST patterns over the Pacific and Atlantic. On the basis of model simulations and statistical analysis of global SST and PDSI, Dai (2013) predicted severe and widespread droughts in worldwide terrestrial ecosystems in the coming decades.

China's drought and its connection with oceanic processes are also under investigation. Li et al. (2015) defined eight climate divisions in the country via clustering algorithms and then examined distinctive regional drought risks modulated by El Niño-Southern Oscillation (ENSO) phases from 1961 to 2012. Wang and $\mathrm{He}$ (2015) discovered that a severe summer drought over northern China and part of northeastern Asia in 2014 was the joint result of Pacific SST and Arctic sea ice anomalies and warming over the European continent and Caspian Sea. Qian and Zhou (2014) contended that PDSI in northern China was negatively correlated with the Pacific decadal oscillation (PDO) during 1900-2010. The aforementioned studies highlight the importance of investigating and evaluating the role of global SST anomalies in the generation and maintenance of prolonged droughts in China. Nevertheless, relevant research at the national scale and a long time scale remains rare.

In China, the physical and economic impacts of drought are most evident during the warm season. Summer is the main rainy season in the country, with the majority of rainfall between April and September. The Dai dataset (Dai 2011b) indicates that precipitation from June to August contributes to nearly two-thirds of the annual precipitation in northern China (Qian and Zhou 2014). Summer is also the main growing season, so sufficient precipitation in that period is vital to crop and vegetation growth. Therefore, this study explored summer PDSI and its connection with global SST.

Observational data suggest strong teleconnections between summer climate variability in East Asia and preceding winter tropical SST. Wang et al. (2000) found that North Pacific SST anomalies developing in winter when El Niño or La Niña matures persist through the following summer, causing anomalously wet or dry conditions around East Asia. Using observations and an atmospheric general circulation model (GCM), Xie et al. (2009) investigated the cause of the lingering ENSO effects during summer over the western IndoPacific and East Asia. Researchers have long suggested that pronounced precipitation anomalies during the summer following an El Niño event tend to take place near the Yangtze River (Fu and Teng 1988; Huang and Wu 1989; Xie et al. 2009). Therefore, we analyzed the connection between preceding winter SST and summer PDSI in China and assess the utility of such SST for summer drought prediction in China.

The singular value decomposition (SVD) technique is useful in decomposing terrestrial drought data and SST fields into leading coupled modes that delineate spatial patterns for their teleconnections (e.g., Rajagopalan et al. 2000; Shabbar and Skinner 2004). However, the temporal variation of neither drought indices nor SSTs is covered in these analyses. To supplement the SVD analysis, the ensemble empirical mode decomposition (EEMD) method is used to detect the temporal variability of dryness or wetness and its connections with oceanic processes. A combination of these two methods is a feasible way to explore the relationships between PDSI patterns and global SST at both temporal and spatial scales. Afterward, multiple linear regression (MLR) is used to explore the relative influence of different SST patterns identified by SVD on drought in China.

Through this combination of methods, we determined spatiotemporal patterns for the linkage of summer moisture availability in China and oceanic processes from 1901 to 2012. We organize the rest of this article as 
TABLE 1. Statistics of SVD analysis for summer (JJA) PDSI in China and concomitant global SST anomalies (1901-2012).

\begin{tabular}{ccccc}
\hline \hline Mode & SCF $(\%)$ & Correlation coefficient & PDSI variance $(\%)$ & SST variance $(\%)$ \\
\hline$S_{1}$ & 57.30 & 0.79 & 13.55 & 53.50 \\
$S_{2}$ & 8.85 & 0.69 & 14.76 & 10.02 \\
$S_{3}$ & 7.86 & 0.66 & 12.99 & 11.17 \\
$S_{4}$ & 4.04 & 0.76 & 12.27 & 4.56 \\
$S_{5}$ & 2.89 & 0.74 & 9.88 & 4.25 \\
\hline
\end{tabular}

follows. First, datasets of PDSI, SST, and oceanic indices are listed in section 2 . Then, brief introductions to the statistical methods, including SVD, EEMD, and MLR, are provided in section 3. In section 4, we use an SVD analysis to identify a group of oceanic processes, consisting of Arctic sea ice loss, global warming, North Pacific Current (NPC), ENSO, and PDO at spatial scale, which are important to summer drought in China. Their temporal scales are then distinguished via EEMD in section 5, along with those of drought area in the country. The relative influences of oceanic factors on Chinese regional drought are identified by MLR in section 6. All findings are summarized in section 7.

\section{Data}

a. PDSI

PDSI data measure prolonged abnormal dryness or wetness across a region. Monthly self-calibrated PDSI data with potential evapotranspiration estimated on the basis of the Penman-Monteith equation (sc_PDSI_pm) were used (Dai 2011b). An updated version of these data for the period 1850-2012 (archived online at http://www.cgd.ucar. edu/cas/catalog/climind/pdsi.html) were calibrated using local climate conditions to replace fixed coefficients derived from the central United States by Palmer (1965). This facilitates spatial comparability (Dai 2011b).

PDSI values generally vary between -4 and +4 , but they may reach -10 or +10 under extreme circumstances. Negative or positive PDSIs indicate dry or wet conditions, respectively. Zero represents normal conditions.

\section{b. Global SST data}

Cosmic Background Explorer SST data on a $1^{\circ}$ latitude $\times 1^{\circ}$ longitude global grid were obtained from the National Oceanic and Atmospheric Administration/ Earth System Research Laboratory/Physical Sciences Division (NOAA/OAR/ESRL/PSD) in Boulder, Colorado, from their website (online at http:/www.esrl.noaa.gov/psd/ data/gridded/data.cobe.html; Folland and Parker 1995; Ishii et al. 2005; Japan Meteorological Agency 2006). Global mean SST anomalies and mean SST anomalies over the NPC (defined in this study as the region $40^{\circ}-50^{\circ} \mathrm{N}$, $150^{\circ} \mathrm{E}-150^{\circ} \mathrm{W}$ ) were both derived from the global SST data.

\section{c. Niño-3.4 index}

The Niño-3.4 index, which is in common use for ENSO activities, measures mean SST over the region bounded by $5^{\circ} \mathrm{S}-5^{\circ} \mathrm{N}, 120^{\circ}-170^{\circ} \mathrm{W}$. (The data used herein were obtained online at http://www.cgd.ucar.edu/cas/catalog/ climind/TNI_N34/index.html\#Sec5 for 1901-2007 and http:/www.esrl.noaa.gov/psd/forecasts/sstlim/Globalsst.html for 1950-2015. The latter series was rescaled to match the former during the overlapping period 1950-2007 to generate a complete data series from 1901 to 2012.)

\section{d. PDO index}

We obtained the monthly PDO index, which is the leading standardized principal component of SST anomalies over the North Pacific, from the University of Washington (online at http://research.jisao.washington.edu/pdo/ PDO.latest). The influence of global warming trends in the data was reduced by removing global mean SST anomalies. Further details are available in Mantua et al. (1997) and Zhang et al. (1997).

\section{e. SIC data}

Monthly mean sea ice concentration (SIC) data on a $1^{\circ}$ latitude $\times 1^{\circ}$ longitude global grid from the NCAR Climate Data Guide: sea ice concentration data from HadISST were used (retrieved online from https://climatedataguide. ucar.edu/climate-data/sea-ice-concentration-data-hadisst; Rayner et al. 2003; Screen 2011).

\section{f. Precipitation and surface air temperature data}

Monthly precipitation $P$ and surface air temperature $T$ data over land on a $0.5^{\circ}$ latitude $\times 0.5^{\circ}$ longitude grid from 1901 to 2012 were from the Climatic Research Unit (CRUTSv3.23; available online at http://catalogue.ceda. ac.uk/uuid/3f8944800cc48e1cbc29a5ee12d8542d; Harris et al. 2014).

\section{Methods}

\section{a. SVD}

We used the SVD method to analyze large-scale relationships between global SST anomalies and summer PDSI in China for the 112-yr period from 
a $\mathbf{S}_{1}$

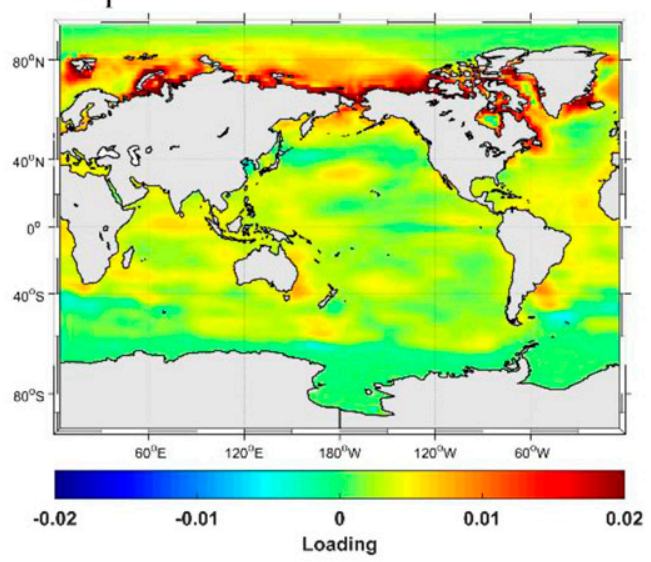

b $\quad \mathrm{S}_{2}$

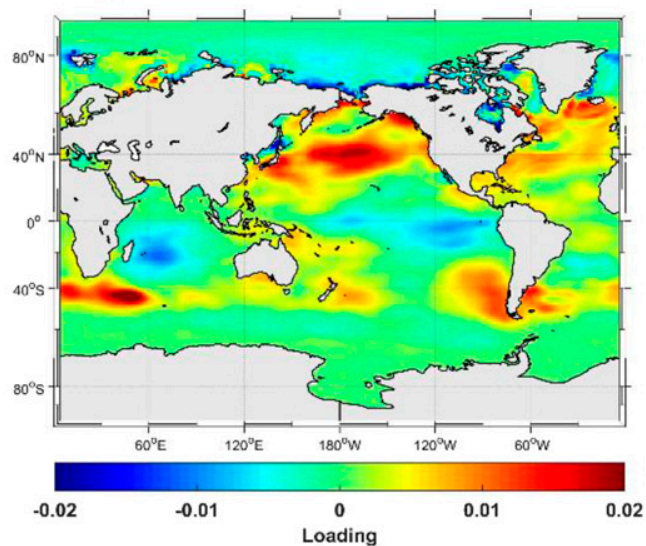

c $\mathrm{S}_{3}$

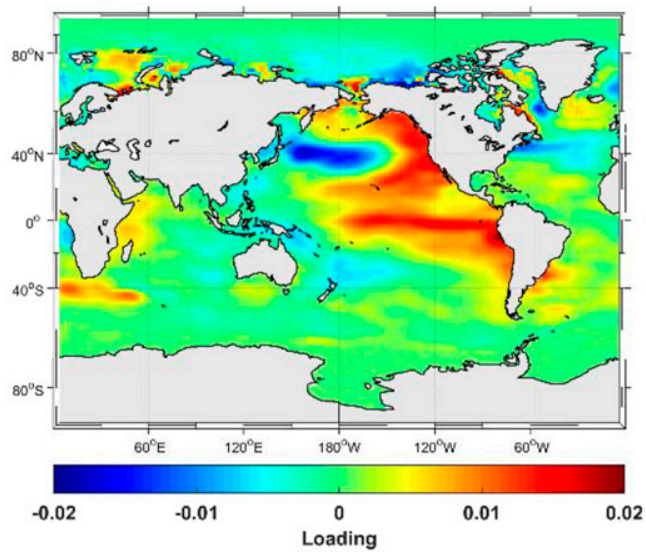

d

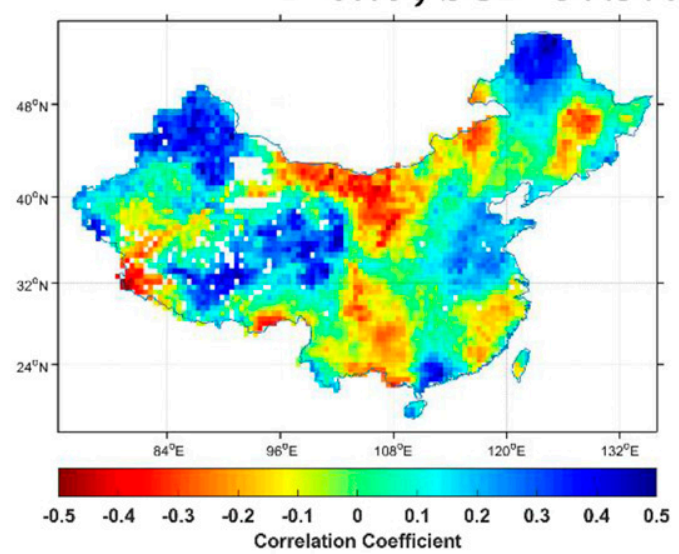

e

$\mathrm{r}=0.69, \mathrm{SCF}=8.8 \%$

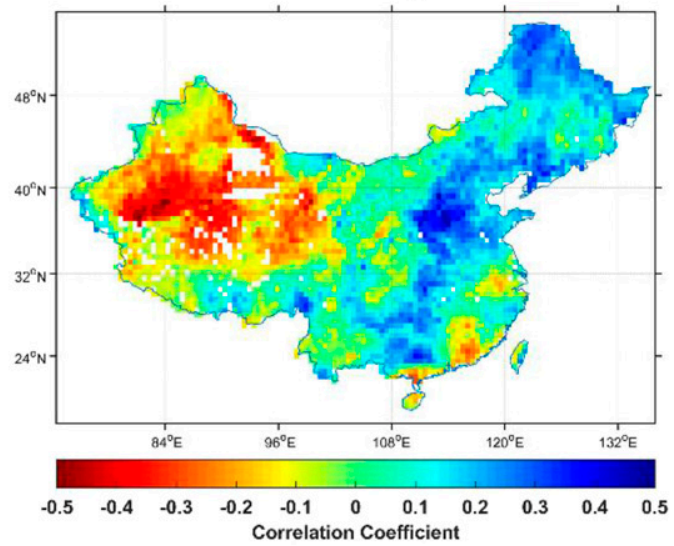

f

$\mathrm{r}=0.66, \mathrm{SCF}=7.9 \%$

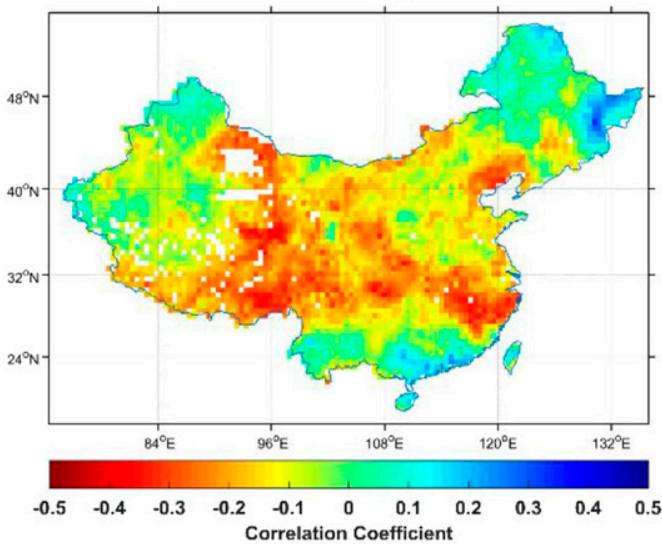

FIG. 2. (a)-(c) Loading maps and (d)-(f) heterogeneous correlation patterns $r$ (PDSI, $\mathrm{SST}_{k}$ ) of leading three SVD modes $S_{1}-S_{3}$ for teleconnections between summer (JJA) PDSI in China and concurrent global SST anomalies (19012012). Temporal correlation coefficient $r$ between corresponding expansion coefficients and SCF are provided for each mode. Pixels with no available PDSI data are colored white in (d)-(f). 
TABLE 2. Statistics of SVD analysis for summer (JJA) PDSI in China and previous winter (DJF) global SST anomalies (1901-2012).

\begin{tabular}{lcccr}
\hline \hline Mode & SCF $(\%)$ & Correlation coefficient & PDSI variance $(\%)$ & SST variance $(\%)$ \\
\hline$W_{1}$ & 52.01 & 0.78 & 6.15 & 26.49 \\
$W_{2}$ & 12.27 & 0.64 & 4.20 & 13.76 \\
$W_{3}$ & 9.01 & 0.75 & 7.45 & 4.19 \\
$W_{4}$ & 4.29 & 0.68 & 6.79 & 2.64 \\
$W_{5}$ & 3.29 & 0.76 & 3.81 & 2.88 \\
\hline
\end{tabular}

1901 to 2012. The SVD decomposes the covariance matrix of two fields into singular values and two sets of paired-orthogonal vectors, the spatial patterns of which are called loading maps. The expansion coefficients for either field are matrix products of the field and its loading map. Covariance between expansion coefficients of the leading pattern in both fields is maximized. Therefore, SVD is also called maximum covariance analysis in the climate literature (e.g., Dai 2013). The squared covariance fraction (SCF), or the proportion of squared covariance explained by a pair of expansion coefficients, can be calculated from the singular value. Connections between both fields are revealed by the spatial patterns of heterogeneous correlations, defined as Pearson correlations between the expansion coefficients of one field and original gridpoint values of the other. In the present study, heterogeneous correlations between the $k$ th expansion coefficients of global SST anomalies and PDSI field in China are denoted by $r$ (PDSI, $\mathrm{SST}_{k}$ ). The spatial pattern of $r\left(\mathrm{PDSI}, \mathrm{SST}_{k}\right)$ indicates how well the PDSI field can be specified on the basis of the $k$ th expansion coefficient of SST anomalies. For further details of the SVD method, please refer to Bretherton et al. (1992).

We smoothed the PDSI and SST data using high-pass and low-pass filters, respectively, and then used SVD analysis of the smoothed data fields to explore the relative effect of ENSO and PDO on Chinese drought. Here, high-pass filtering was performed via a Butterworth filter (Butterworth 1930) that removes variations on 7-yr and longer time scales, and low-pass filtering was done via 9-yr running average. Results using 7- or 11-yr running averages (instead of 9-yr running average) were similar and thus not discussed below.

Although the SVD analysis was able to identify the relationship between global SST and drought in China, it cannot reflect lingering effects of various oceanic processes on Chinese summer drought. Therefore, we conducted the SVD analysis twice to study the connections between summer moisture availability in the country and both contemporary SST fields and SST fields of the preceding winter.

\section{b. EEMD}

The EEMD method introduced by $\mathrm{Wu}$ and Huang (2009) was used to analyze the time scales at which different SST patterns identified by SVD can influence overall summer drought in China. EEMD is an improvement of empirical mode decomposition (EMD; Huang et al. 1998), which is an adaptive time-frequency analysis algorithm that decomposes a time series into various intrinsic mode functions (IMFs) with different time scales. Compared to EMD, EEMD adds multiple white-noise realizations to targeted data and uses an ensemble average approach for corresponding IMFs extracted via EMD. The global frequency or mean period of each IMF can be calculated using the Hilbert transform. See $\mathrm{Wu}$ and Huang (2009) for further details. EEMD has been proven effective in revealing variability at different time scales in previous studies (e.g., Wu et al. 2011; Qian et al. 2011). In our study, the ratio of amplitude of the added noise and that of the targeted time series was 0.2 , and the ensemble number was 100. Because of strong autocorrelations of EEMD components, we performed significance tests of temporal correlations based on the effective sample size, also known as effective degrees of freedom, which are calculated by

$$
\operatorname{dof}=\frac{N}{\sum_{\tau=-(N-1)}^{N-1}(1-|\tau| / N) \rho_{\tau}^{X} \rho_{\tau}^{Y}},
$$

where dof is effective degrees of freedom, $N$ is the length of the time series, and $\rho_{\tau}^{X}$ and $\rho_{\tau}^{Y}$ are autocorrelations of the two time series, respectively, at a time lag of $\tau$ (Bretherton et al. 1999).

\section{c. $M L R$}

MLR aims to determine the relative importance of different independent variables in explaining the dependent variable (Clow 2010). Because the PDSI and SST data are long time series, for which assuming a high-frequency signal has little effect, we focused on low-frequency decadal and multidecadal variations when analyzing the influence of various modes derived from SVD on Chinese regional drought. Here, MLR was used to clarify the relationship between low-pass-filtered PDSI and the expansion coefficients of the leading three SVD patterns of low-passfiltered SST. Prior to applying this method, we normalized the low-pass-filtered data using standardized $z$ scores. The general equation of multiple linear regression is 
$\mathbf{a}$

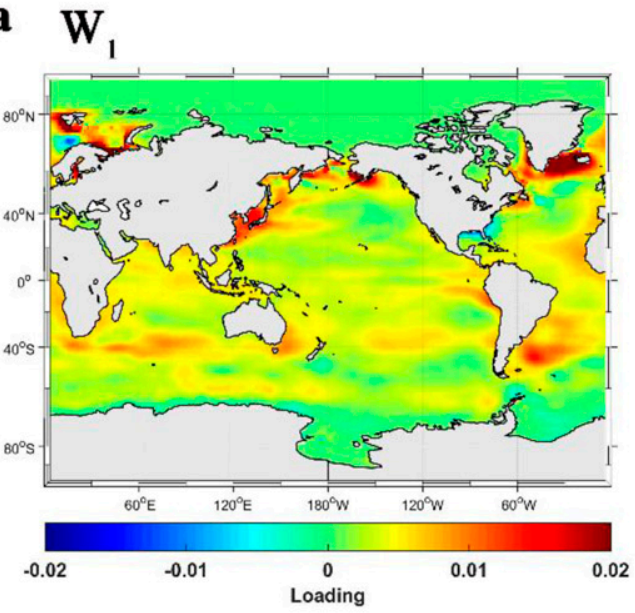

b $\mathrm{W}_{2}$

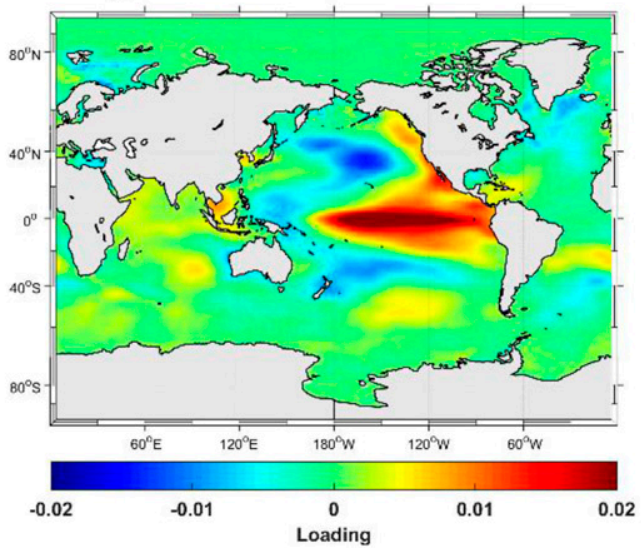

c $\mathrm{W}_{3}$

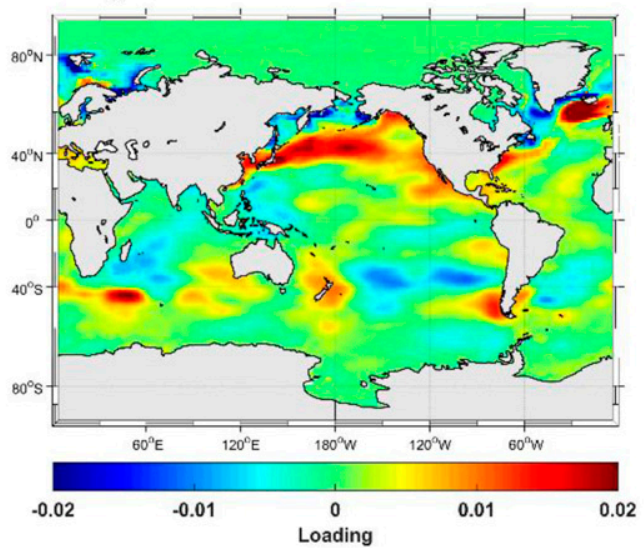

d

$\mathrm{r}=0.78, \mathrm{SCF}=52.0 \%$
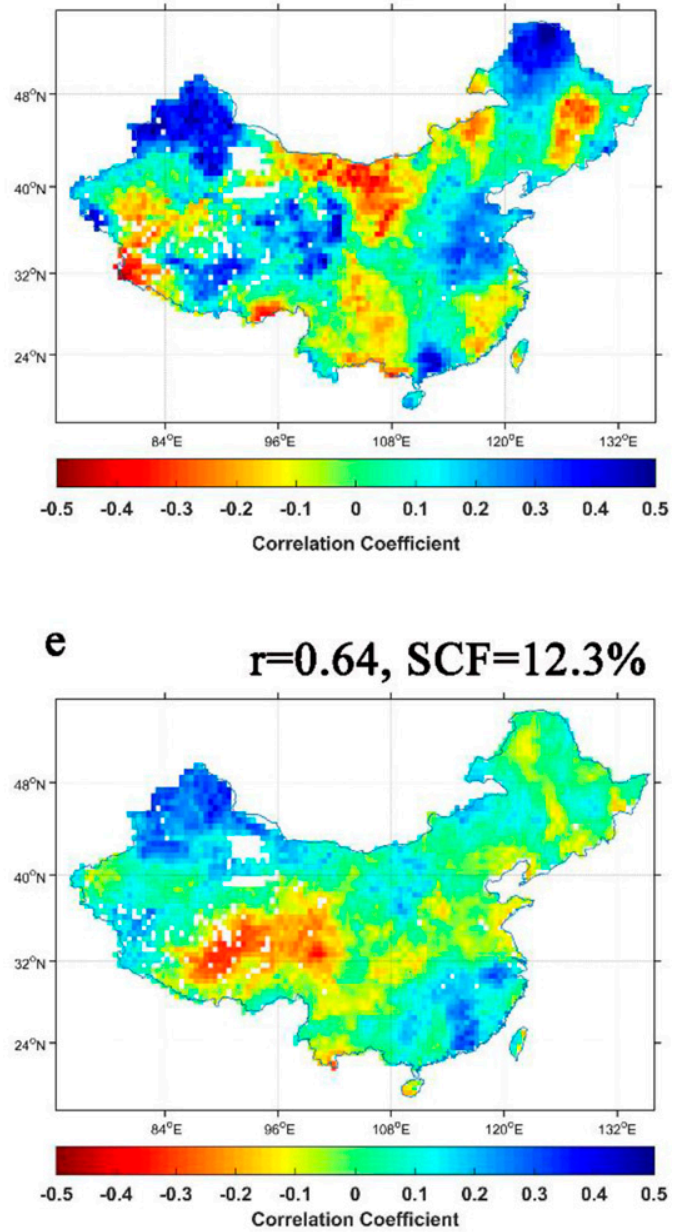

f

$\mathrm{r}=0.75, \mathrm{SCF}=9.0 \%$

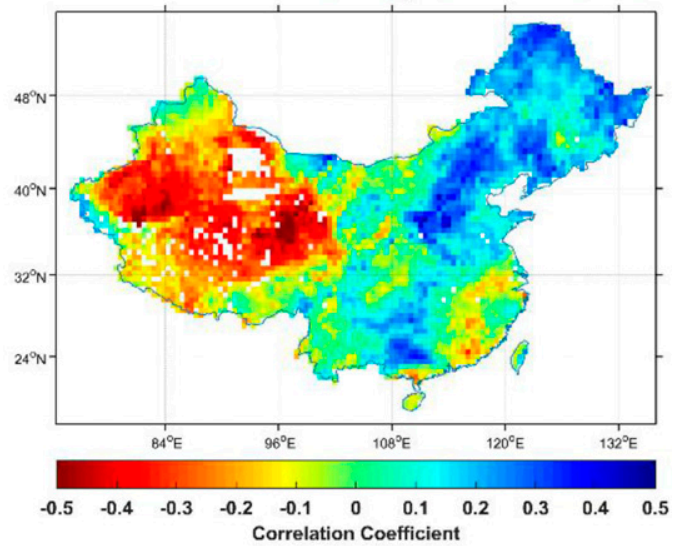

FIG. 3. (a)-(c) Loading maps and (d)-(f) heterogeneous correlation patterns $r$ (PDSI, $\mathrm{SST}_{k}$ ) of the leading three SVD modes $W_{1}-W_{3}$ for teleconnections between summer (JJA) PDSI in China and previous winter (DJF) global SST anomalies (1901-2012). Temporal correlation coefficient $r$ between corresponding expansion coefficients and SCF are provided for each mode. Pixels with no available PDSI data are colored white in (d)-(f). 

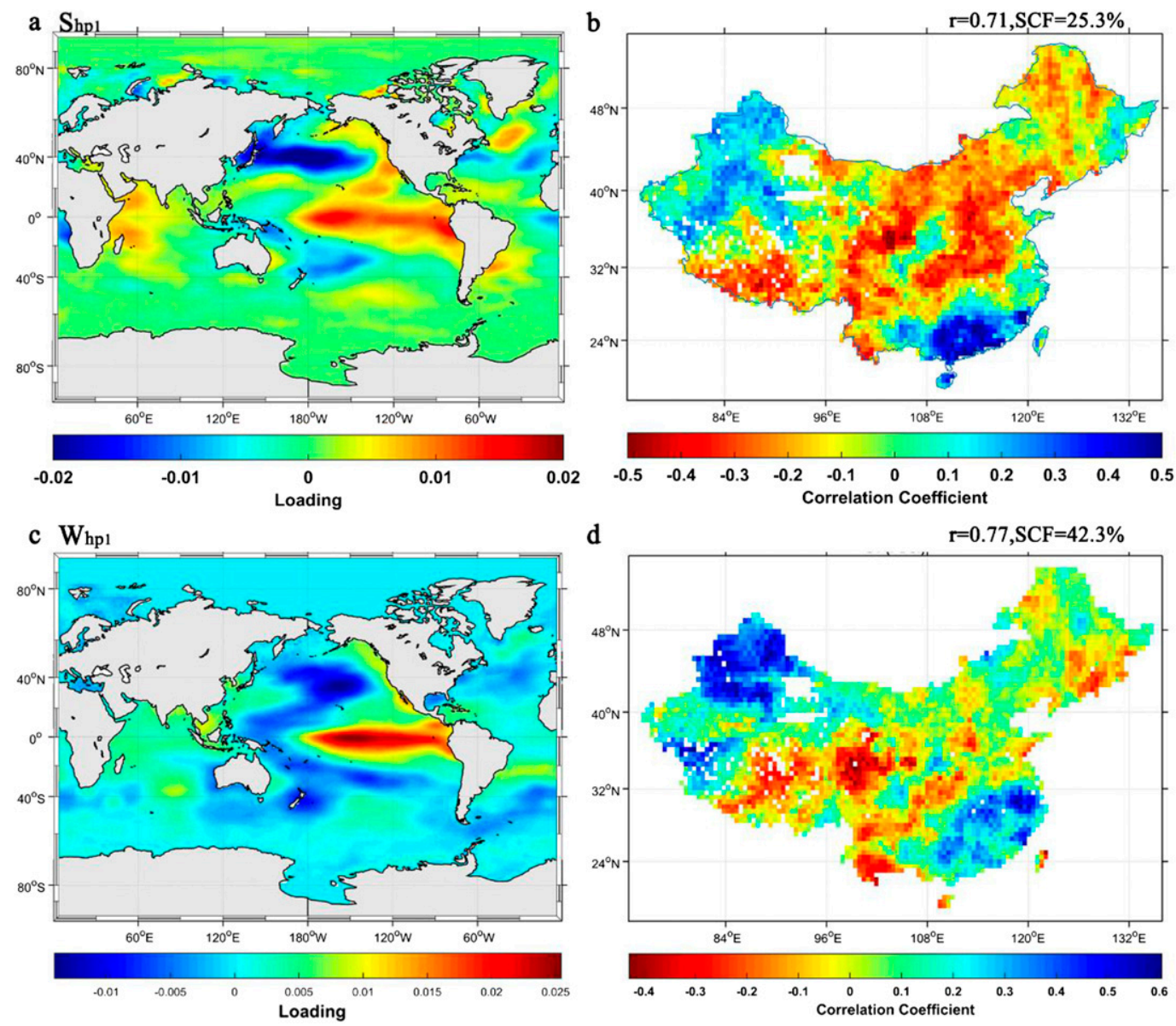

FIG. 4. (a),(c) Loading maps and (b),(d) heterogeneous correlation patterns $r\left(\mathrm{PDSI}, \mathrm{SST}_{k}\right.$ ) of the first SVD mode for the teleconnections between high-pass-filtered summer (JJA) PDSI in China and concurrent (previous winter) global SST anomalies (1901-2012). The temporal correlation coefficient $r$ between the corresponding expansion coefficients and the SCF are provided for each mode. Pixels with no available PDSI data are colored white in (b),(d).

$$
\operatorname{PDSI}^{\prime}=c_{1} F_{1}+c_{2} F_{2}+c_{3} F_{3}+a,
$$

where PDSI $^{\prime}$ is the normalized dependent variable of low-pass-filtered PDSI; $F_{1}, F_{2}$, and $F_{3}$ are the normalized expansion coefficients of the leading three SVD patterns of low-pass-filtered SST (the sea ice loss-global warming, NPC, and PDO patterns, respectively); $c_{1}, c_{2}$, and $c_{3}$ are the regression coefficients; and $a$ is the regression constant. The statistical significance of the regression model is assessed by means of a Fisher $(\mathrm{F})$ test, with the residual sequence accounted for by the Durbin-Watson test (Draper et al. 1966, 217-220). Statistical variable independence was verified by a variance inflation factor test to avoid multicollinearity (Engle 1982).

\section{d. TS median slope}

The Theil-Sen (TS) median slope measures the linear trend of summer PDSI from 1901 to 2012 for each pixel and aids understanding of the heterogeneous correlation pattern for summer PDSI in China in the first SVD mode. It is a type of nonparametric statistics for the trend of a complete time series and calculates the median of slopes between all pairs of observations. Details of the algorithm are available in Hoaglin et al. (1983). This procedure is commonly used to estimate trends of time series with seasonality, skewness, heteroscedasticity, and temporal autocorrelation (e.g., Alcaraz-Segura et al. 2010; Fensholt and Proud 2012; Liu et al. 2015).

\section{Spatial analysis of the relationship between summer drought in China and global SST using SVD}

a. SVD patterns of summer (or previous winter) unfiltered SST and their connections with summer drought in China

Statistics of the SVD analysis are summarized in Table 1. It is clear that the SCFs of the first three modes 
TABLE 3. Statistics of SVD analysis for low-pass-filtered summer (JJA) PDSI in China and concomitant global SST anomalies (1901-2012).

\begin{tabular}{ccccr}
\hline \hline Mode & SCF (\%) & Correlation coefficient & PDSI variance (\%) & SST variance (\%) \\
\hline$S_{1}^{\prime}$ & 76.60 & 0.90 & 17.94 & 67.08 \\
$S_{2}^{\prime}$ & 9.99 & 0.86 & 17.34 & 10.12 \\
$S_{3}^{\prime}$ & 3.44 & 0.92 & 8.10 & 6.49 \\
\hline
\end{tabular}

are much larger than the others and they account for approximately $74 \%$ of the total squared covariance, signifying the importance of the three modes in the relationship between PDSI and SST variability. Moreover, the correlation coefficients were all greater than 0.6 ( $p$ value $<10^{-11}$ ) for the first three modes.

The spatial pattern associated with the first SST mode, $S_{1}$ (where $S$ is an abbreviation for summer), is shown in Fig. 2a. With positive and even loadings nearly everywhere, especially the Arctic Circle, this identifies the signal of Arctic sea ice loss and global warming. This is consequently called the sea ice loss-global warming pattern. This signal accounts for greater than $50 \%$ of the squared covariance, which makes Arctic sea ice loss and global warming the most crucial factors in explaining summer moisture variability over China. Both the second and third modes of SST have strong loading in the Pacific. The second mode is strong over the North Pacific, especially the Kuroshio and the NPC regions, and is therefore termed as the "NPC pattern" (Fig. 2b), while the third mode has a pattern that resembles the coupled ocean-atmosphere variability pattern associated with PDO and ENSO and is referred to as the "PDO-ENSO pattern" (Fig. 2c).

In Figs. 2d-f, we find the heterogeneous correlation patterns $r$ (PDSI, $\mathrm{SST}_{k}$ ) associated with the leading three modes. In the sea ice loss-global warming pattern, the northern part of northeastern China, northern China, Xinjiang region, eastern Tibetan Plateau, and Pearl River delta become wetter with Arctic sea ice loss or rise in global SST. In contrast, there is a moisture deficit in the rest of China, especially in Inner Mongolia where drought forecasts are vital for farmers (Fig. 2d). The heterogeneous pattern of the NPC mode in Fig. 2e indicates that warmer surface water in the NPC region leads to an increase in summer PDSI over eastern China and a decrease across the Tibetan Plateau and Xinjiang region. The last heterogeneous pattern, for the PDOENSO mode, is displayed in Fig. 2f. It reveals that the warm phases of ENSO or PDO lead to drought in summer across China, except for the northeast and extreme south.

Table 2 lists statistics from the SVD analysis. The first three modes account for approximately $73 \%$ of the squared covariance. Correlation coefficients between the expansion coefficients are greater than 0.6 $\left(p\right.$ value $\left.<10^{-11}\right)$ for all three modes.

The first mode, $W_{1}$ (where $W$ is an abbreviation for winter; Fig. 3a), identifies a global warming signal that is similar to the pattern $S_{1}$. The heterogeneous correlation map (Fig. 3d) associated with $W_{1}$ is also similar to that associated with $S_{1}$. However, the next two modes, $W_{2}$ (Fig. 3b) and $W_{3}$ (Fig. 3c), are similar to $S_{3}$ and $S_{2}$, respectively; that is, the order of the modes is reversed compared to that determined for summer SST. Whereas the heterogeneous correlation associated with the winter NPC mode $W_{3}$ (Fig. 3f) is similar to that associated with the summer NPC mode $\left(S_{2}\right)$, the heterogeneous correlation associated with the winter PDO-ENSO mode $W_{2}$ (Fig. 3e) is quite different from that associated with the summer PDO-ENSO mode $\left(S_{3}\right)$. Rather than drying in summer over almost the whole China associated with the contemporary El Niño or positive PDO events $\left(S_{3}\right)$, the winter warm events lead to relatively strong drying in the following summer only over the Tibetan Plateau.

\section{b. SVD patterns of summer (or previous winter) filtered SST and their connections with summer drought in China}

The relationship between ENSO and PDO is a subject of debate, with some researchers arguing that the

TABLE 4. Statistics of SVD analysis for low-pass-filtered summer (JJA) PDSI in China and previous winter (DJF) global SST anomalies (1901-2012).

\begin{tabular}{ccccr}
\hline \hline Mode & SCF $(\%)$ & Correlation coefficient & PDSI variance (\%) & SST variance $(\%)$ \\
\hline$W_{1}^{\prime}$ & 72.70 & 0.89 & 17.33 & 63.79 \\
$W_{2}^{\prime}$ & 11.54 & 0.86 & 18.20 & 10.21 \\
$W_{3}^{\prime}$ & 4.15 & 0.87 & 9.11 & 7.19 \\
\hline
\end{tabular}



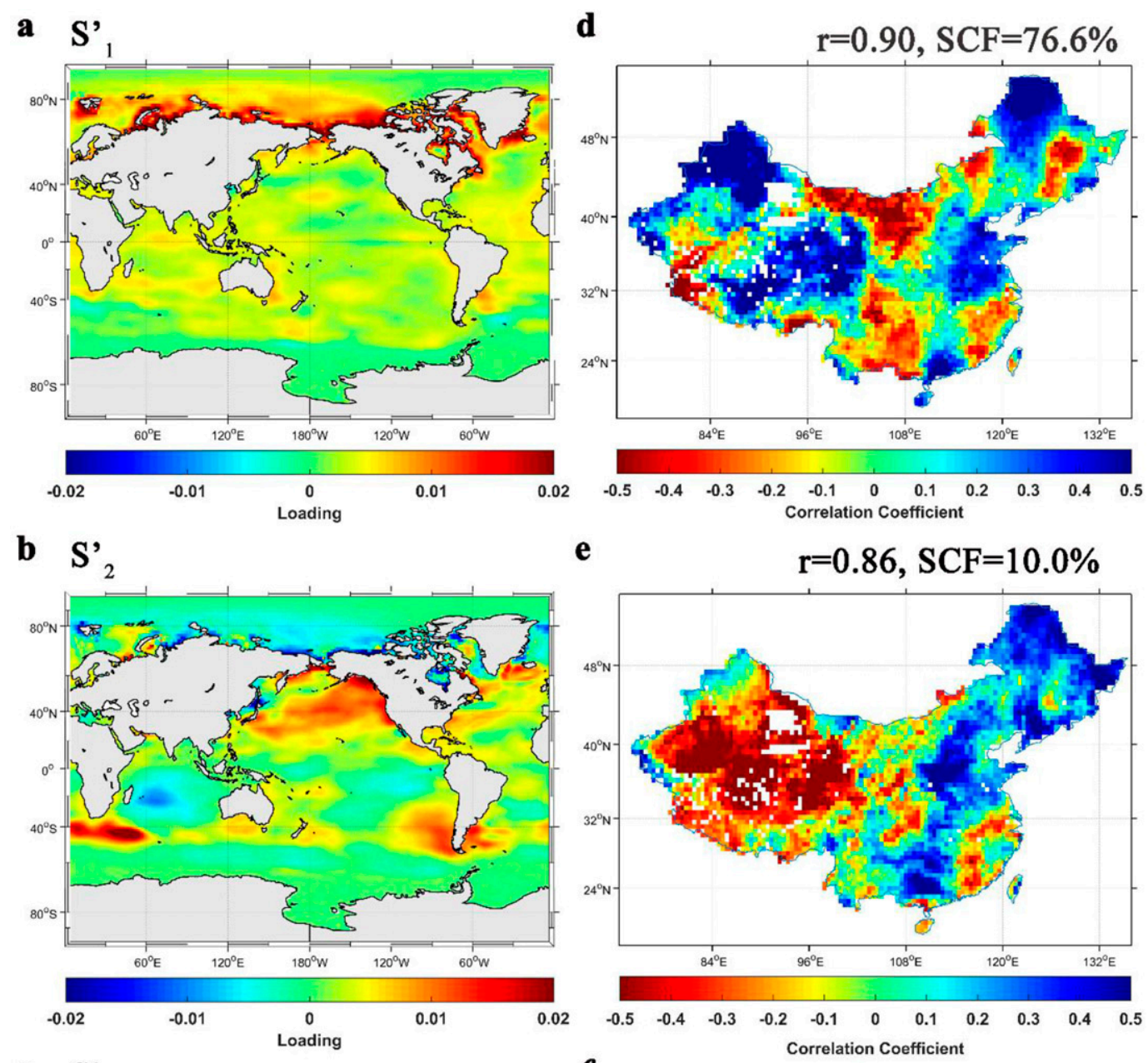

c $\quad \mathbf{S}_{3}$
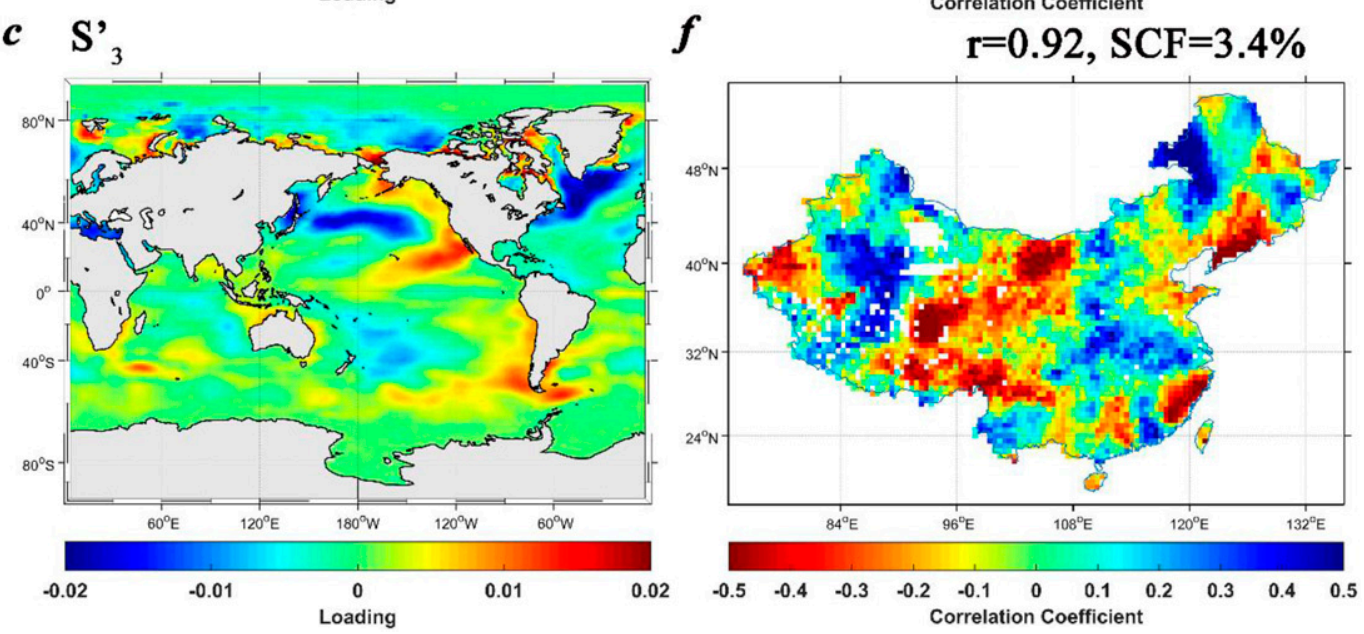

FIG. 5. (a)-(c) Loading maps and (d)-(f) heterogeneous correlation patterns $r$ (PDSI, SST $_{k}$ ) of the leading three SVD modes $S_{1}^{\prime}-S_{3}^{\prime}$ for teleconnections between low-pass summer (JJA) PDSI in China and concurrent low-pass global SST anomalies (1901-2012). Temporal correlation coefficient $r$ between corresponding expansion coefficients and SCF are provided for each mode. Pixels with no available PDSI data are colored white in (d)-(f). 

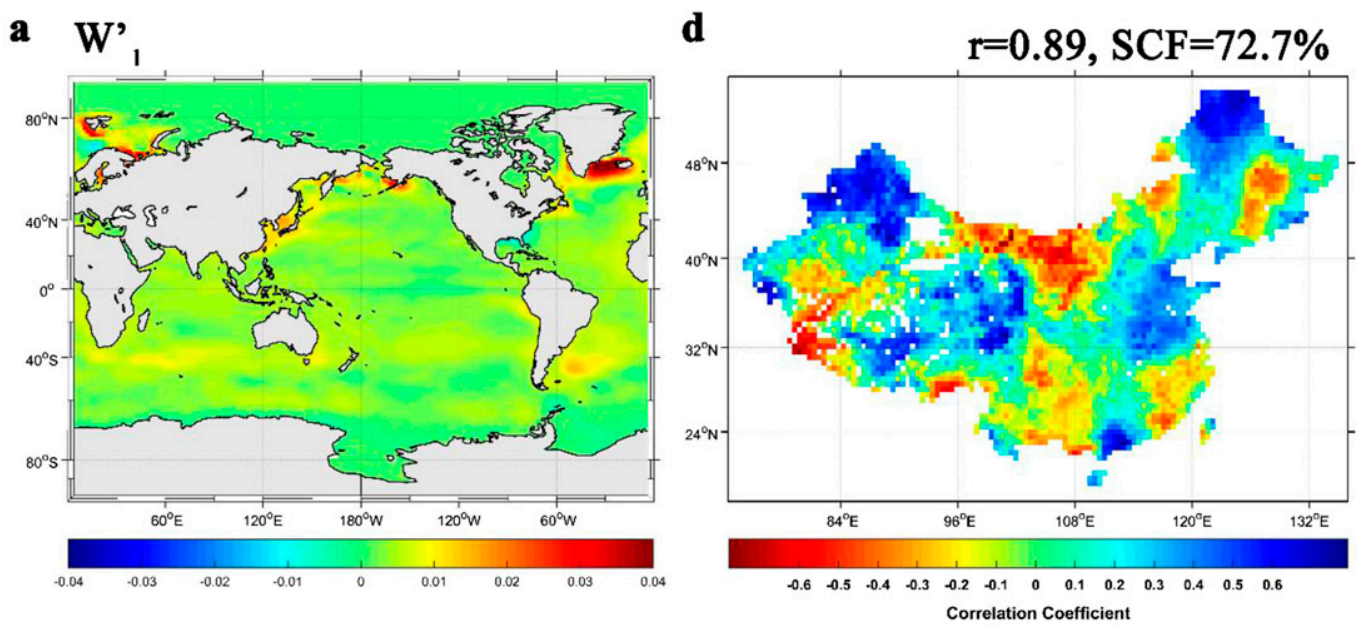

b $\mathbf{W}^{\prime}$,

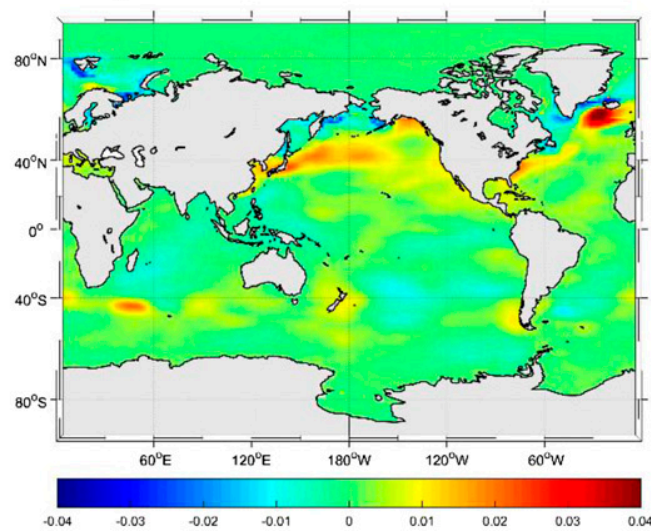

$\mathbf{e}$

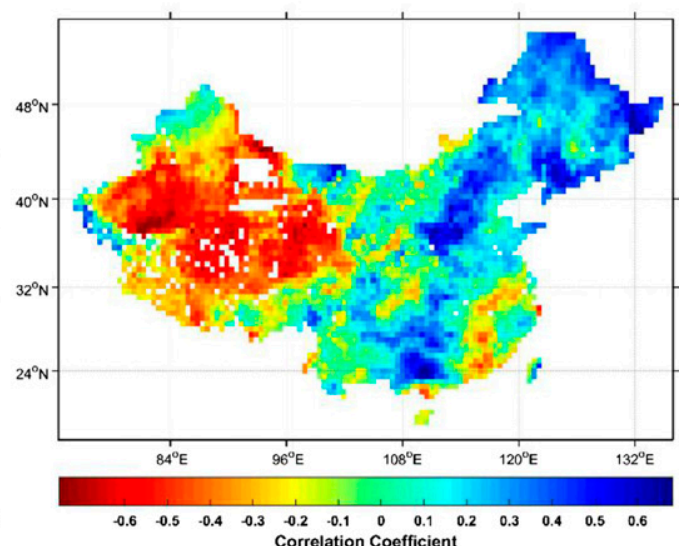

c $\quad \mathbf{W}_{3}{ }_{3}$

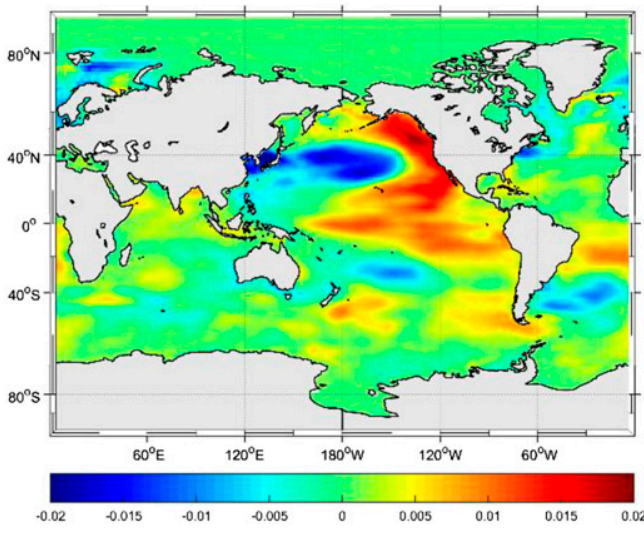

$\boldsymbol{f}$

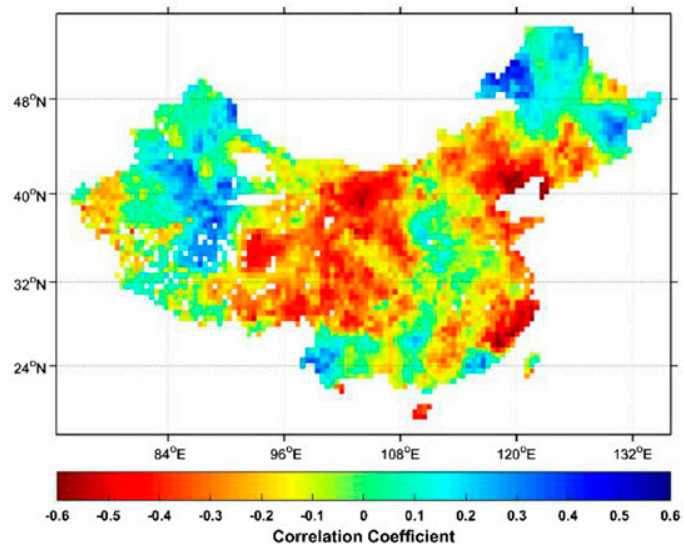

FIG. 6. (a)-(c) Loading maps and (d)-(f) heterogeneous correlation patterns $r$ (PDSI, $\mathrm{SST}_{k}$ ) of the leading three SVD modes $W_{1}^{\prime}-W_{3}^{\prime}$ for teleconnections between low-pass summer (JJA) PDSI in China and previous winter (DJF) low-pass global SST anomalies (1901-2012). Temporal correlation coefficient $r$ between corresponding expansion coefficients and SCF are provided for each mode. Pixels with no available PDSI data are colored white in (d)-(f). 


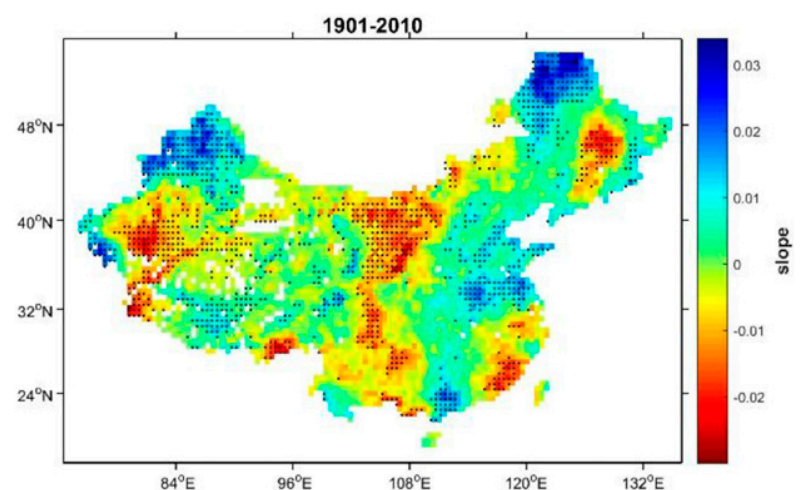

FIG. 7. Annual rates of change of summer PDSI measured using Theil-Sen median slopes (1901-2012). Pixels where trend is significant at 0.05 level are shown with stippling.

ENSO-like pattern of the PDO or interdecadal Pacific oscillation (IPO) is a residual one resulting from spatial asymmetries of ENSO and the skewness in ENSO statistics (Meehl et al. 2014). Conversely, other studies suggest that decadal changes in the tropical Pacific mean state are forced by separate mechanisms and may influence the amplitude and frequency of ENSO (Power et al. 1999; Meehl and Hu 2006; Matei et al. 2008; Meehl et al. 2010, 2014). Further, $S_{3}$ and $W_{2}$ contain both ENSO-related interannual variations and PDO-related decadal-multidecadal oscillations. Here, we may quantify the contribution of PDO and ENSO separately because they act at different time scales. As an interannual oscillation, ENSO would account for much of the correlation between Chinese PDSI and global SST at a high frequency. By contrast, the PDO could affect this teleconnection at a low frequency. To explore the relative contributions of ENSO and PDO to summer drought over China, we applied SVD analyses to high-passfiltered $(<9 \mathrm{yr})$ and low-pass-filtered ( $>9 \mathrm{yr})$ PDSI and global SST, respectively.

For the high-pass-filtered datasets, ENSO became the first mode in the SVD analysis (Fig. 4). The $S_{\mathrm{hp} 1}$ and $W_{\mathrm{hp} 1}$ are similar to $S_{3}$ and $W_{2}$, respectively, while the heterogeneous correlations become stronger. As shown in $S_{\mathrm{hp} 1}$ and $W_{\mathrm{hp} 1}$, either El Niño in concurrent summer or previous winter will generate a wet monsoon over southern China and a dry one over the north, which is consistent with Ahn and Lee (2002) and Lim and Kim (2007). In the current study we are interested in the change of drought on longer time scales than interannual, so will not discuss ENSO further. We focus on the influence of interdecadal PDO on summer drought in China, assuming that interannual ENSO variability does not have a significant long-term effect. We did the SVD analyses again on the 9-yr running-average summer PDSI in China and concurrent (or previous winter)
SST anomalies, with main summary statistics shown in Tables 3 and 4 (summer and previous winter, respectively). Sum of the SCFs of the first three modes increased to approximately $88 \%$ and the correlation coefficients increased to greater than 0.85 ( $p$ value $<10^{-11}$ ) for all three modes in both seasons.

Unlike the SVD analysis on the unfiltered datasets where summer mode $S_{2}$ is accordant to winter mode $W_{3}$, for the low-pass-filtered the datasets, the order of modes is the same for summer and the previous winter (i.e., $S_{2}^{\prime}$ is accordant to $W_{2}^{\prime}$; Figs. 5 and 6). This therefore provides a consistent result as to how strongly each physical mode influences drought over China, whether the summer or winter SST data are used. The leading three low-pass modes are the sea ice loss-global warming, NPC, and PDO modes, respectively (Figs. 5 and 6). The low-pass sea ice loss-global warming $\left(S_{1}^{\prime}\right.$ and $\left.W_{1}^{\prime}\right)$ and NPC $\left(S_{2}^{\prime}\right.$ and $\left.W_{2}^{\prime}\right)$ modes in both seasons are similar to the spatial patterns of $S_{1}\left(W_{1}\right)$ and $S_{2}\left(W_{3}\right)$ and the SCFs increased. For the PDO mode, the SCFs in both seasons decreased. It is clear that the PDO-like positive phase lead to a summer moisture deficit across the eastern Tibetan Plateau (Figs. 5f and 6f).

The advantage of doing a parallel analysis with previous winter SST data is apparent by comparing Figs. 6 and 5. From the $S_{2}^{\prime}$ mode in Fig. 5 we cannot say clearly what the cause is for this mode, while from $W_{2}^{\prime}$ we may confidently attribute the mode to the variation of the Kuroshio. Similarly, the analysis of the previous-winter SST data gives us confidence that the mode $S_{3}^{\prime}$ from the summer SST is associated with PDO. Moreover, detailed analyses of time series of dry area and oceanic factors, as will be presented in what follows, demonstrate that the winter SST data often give better signals than the summer SST data.

\section{c. Discussion of SVD analysis on low-pass-filtered SST and PDSI}

The driving factors of summer (Fig. 5) and winter (Fig. 6) patterns are strongly related. In the first mode ( $S_{1}^{\prime}$ and $\left.W_{1}^{\prime}\right)$, warming at high latitudes is greater in summer than in winter, probably linked to enhanced Arctic sea ice loss in the summer under global warming (e.g., Serreze et al. 2009; Screen and Simmonds 2010). The difference in mean SIC between the 2000s and 1970s during summer (winter) (see Fig. S1 in the supplemental material) has a similar spatial pattern to $S_{1}^{\prime}\left(W_{1}^{\prime}\right)$. Therefore, although there is some large difference between $S_{1}^{\prime}$ and $W_{1}^{\prime}$, they should both be driven by global warming. Moreover, we conducted SVD analysis of Arctic SIC anomalies in summer or the previous winter and Chinese summer PDSI from 1901 to 2012. Heterogeneous correlation patterns for PDSI (see Fig. S2 in the 

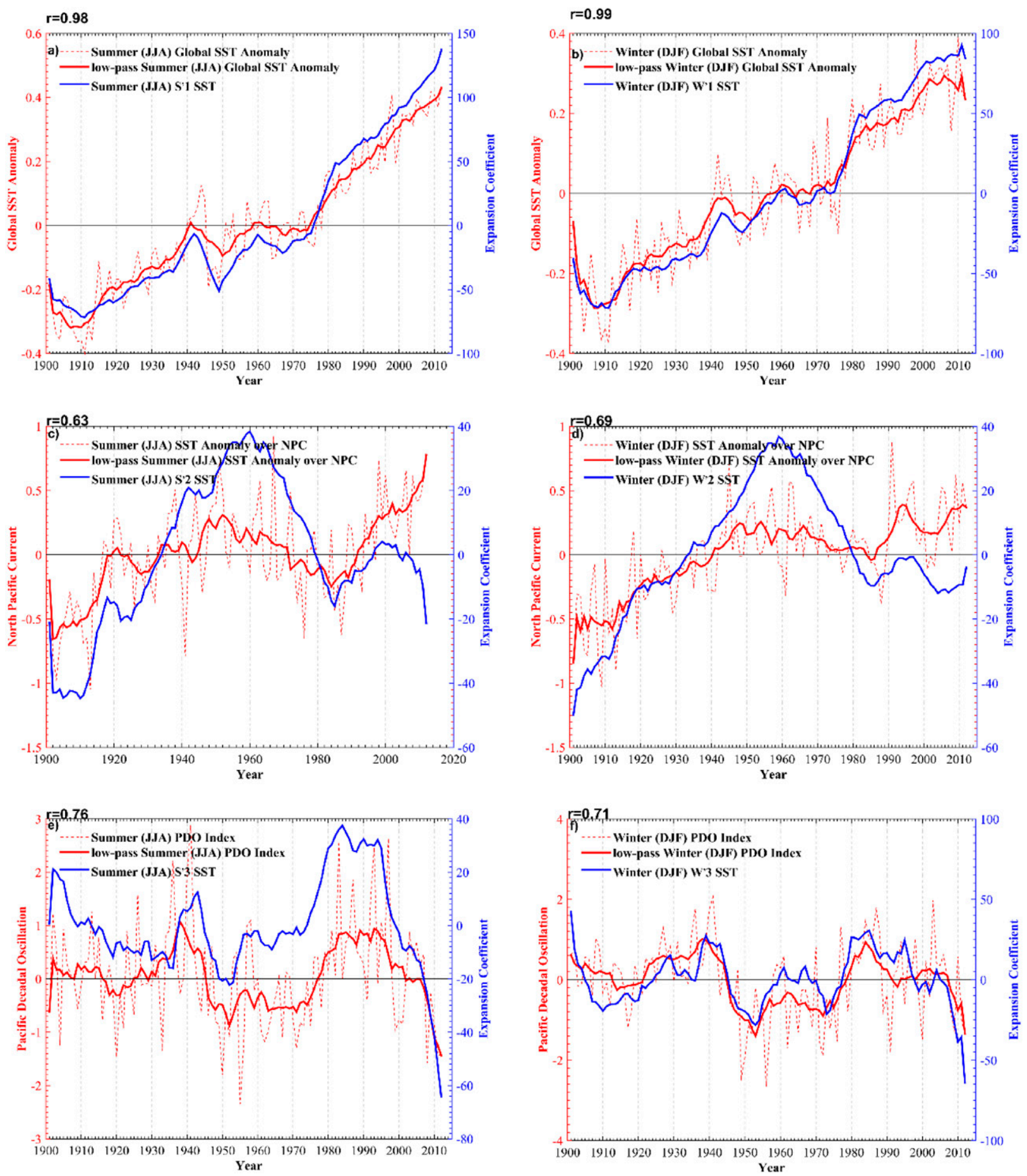

FIG. 8. Expansion coefficients of six SVD patterns for low-pass global SST ( $S_{1}^{\prime}-S_{3}^{\prime}$ and $W_{1}^{\prime}-W_{3}^{\prime}$ ) and corresponding indices (1901-2012). (a) Expansion coefficient for $S_{1}^{\prime}$ and summer (JJA) global mean SST, (b) expansion coefficient for $W_{1}^{\prime}$ and winter (DJF) global SST, (c) expansion coefficient for $S_{2}^{\prime}$ and summer SST over NPC, (d) expansion coefficient for $W_{2}^{\prime}$ and winter SST over NPC, (e) expansion coefficient for $S_{3}^{\prime}$ and summer PDO indices, and (f) expansion coefficient for $W_{3}^{\prime}$ and winter PDO indices. Correlation coefficient $r$ between the two time series is provided at the top left for each panel. In each panel, the dashed red line indicates the original oceanic factor and the solid red line indicates low-pass oceanic factor. 
TABLE 5. Mean periods and their variance contributions (in parentheses) of EEMD modes for percentage dry areas in summer (JJA) over China (1901-2012) and the nonlinear trend. Here, dry area is locally defined as a case in which PDSI is less than the value of the 20th percentile of each pixel, whereas dry area II is defined by PDSI $<-2.0$.

\begin{tabular}{lcr}
\hline \hline Mode & Dry area & Dry area II \\
\hline M1 & $3.8 \mathrm{yr}(40.7 \%)$ & $4.4 \mathrm{yr}(41.3 \%)$ \\
M2 & $12.3 \mathrm{yr}(14.7 \%)$ & $11.2 \mathrm{yr}(13.7 \%)$ \\
M3 & $19.5 \mathrm{yr}(15.8 \%)$ & $21.1 \mathrm{yr}(21.6 \%)$ \\
M4 & $41.4 \mathrm{yr}(11.0 \%)$ & $45.8 \mathrm{yr}(13.8 \%)$ \\
M5 & $78.2 \mathrm{yr}(5.9 \%)$ & $85.1 \mathrm{yr}(0.8 \%)$ \\
Trend & $11.9 \%$ & $8.8 \%$ \\
\hline
\end{tabular}

supplemental material) resemble those in $S_{1}^{\prime}$ and $W_{1}^{\prime}$ very well. Since the change of sea ice is intrinsically related to global warming, the SVD analyses performed here is not able to distinguish the influence of sea ice and global warming on summer drought over China.

The role of global warming in determining the moisture budget in China on decadal time scale has been examined in a number of studies (e.g., Zhao et al. 2010; Qu et al. 2014). Based on simulations of 16 models from phase 5 of the Coupled Model Intercomparison Project (CMIP5) under global warming, Qu et al. (2014) concluded that summer rainfall over northern and northeastern China increases robustly because of enhanced evaporation. They also predicted drier summers over southern and central China. Their analyses did not include the Arctic region, but their results are consistent with the heterogeneous pattern associated with $S_{1}^{\prime}$ (Fig. 5d). To corroborate our argument that this heterogeneous pattern is intimately related to global warming, we estimated linear trends of summer PDSI from 1901 to 2012 for each pixel, using the Theil-Sen procedure. Figure 7 shows annual rates of change in summer PDSI of China from 1901 to 2012 and the results of significance testing. The pattern is indeed very similar to the heterogeneous correlation patterns of $S_{1}^{\prime}$ (Fig. 5d) and $W_{1}^{\prime}$ (Fig. 6d).

The Kuroshio is probably the main source of the NPC mode. Linkage between the Kuroshio and the moisture budget in China has been addressed in recent years.
Zhou and Wang (2014) stated that positive anomalies in the Kuroshio region strengthened the western Pacific subtropical high and increased moisture that was transported from the Bohai Sea and central Pacific, thereby enhancing precipitation in northeastern China. Analogously, Ying et al. (2013) identified Kuroshiorelated evolution as dominating the variation of summer rainfall in the Yangtze-Huaihe River valley.

Ma (2007) studied the relationship between moisture conditions of the central part of northern China and PDO from 1951 to 2005, concluding that the positive PDO phase matched with warm and drought periods and that the decadal SST variation over the North Pacific is one possible cause of the decadal wetness shift over the central part of northern China. Qian and Zhou (2014) analyzed PDO forcing on drought in northern China and found a stable inverse relationship between multidecadal variability of PDSI and that of PDO, consistent with our results. Qian and Zhou (2014) found that composite differences between two positive PDO phases (1922-45 and 1977-2002) and one negative PDO phase (1946-76) in summer exhibit a pattern like an anomalous Pacific-Japan/East Asia-Pacific (PJ/EAP) meridional teleconnections along the East Asian coast. This teleconnection might develop locally in response to the PDO-associated warm SST anomalies in the tropical Indo-Pacific Ocean. Following the PJ/EAP teleconnection patterns, northern China is dominated by an anomalous high pressure and anticyclone system at midto-low levels, which are favorable for dry conditions. A weakened land-sea thermal contrast in East Asia during the transition from negative to positive PDO phase also contributes to the dry conditions in northern China by weakening the East Asian summer monsoon (Qian and Zhou 2014).

Figure 8 shows the temporal structure of SVD modes for low-pass global SST anomalies. Plotted on these charts are the expansion coefficients of the six SVD modes for low-pass global SST $\left(S_{1}^{\prime}-S_{3}^{\prime}\right.$ and $\left.W_{1}^{\prime}-W_{3}^{\prime}\right)$, along with corresponding indices (global mean SST anomalies corresponding to the sea ice loss-global warming pattern, mean SST anomalies over the NPC

TABLE 6. Mean periods and their variance contributions (in parentheses) of EEMD modes and the nonlinear trend for global mean SST anomalies, mean SST anomalies over NPC, PDO index, and Niño-3.4 in summer (JJA) (1901-2012).

\begin{tabular}{lccrr}
\hline \hline Mode & Global warming & NPC & PDO & ENSO \\
\hline M1 & $3.8 \mathrm{yr}(3.2 \%)$ & $5.0 \mathrm{yr}(18.1 \%)$ & $4.5 \mathrm{yr}(48.2 \%)$ & $4.7 \mathrm{yr}(72.3 \%)$ \\
M2 & $9.4 \mathrm{yr}(1.9 \%)$ & $7.3 \mathrm{yr}(8.4 \%)$ & $8.2 \mathrm{yr}(17.0 \%)$ & $9.1 \mathrm{yr}(16.7 \%)$ \\
M3 & $17.1 \mathrm{yr}(1.3 \%)$ & $15.8 \mathrm{yr}(6.2 \%)$ & $16.6 \mathrm{yr}(12.6 \%)$ & $14.8 \mathrm{yr}(6.1 \%)$ \\
M4 & $50.7 \mathrm{yr}(0.6 \%)$ & $44.9 \mathrm{yr}(4.9 \%)$ & $43.4 \mathrm{yr}(16.4 \%)$ & $38.8 \mathrm{yr}(3.9 \%)$ \\
M5 & $87.9 \mathrm{yr}(3.0 \%)$ & $107.0 \mathrm{yr}(16.0 \%)$ & $64.4 \mathrm{yr}(5.5 \%)$ & $67.3 \mathrm{yr}(0.8 \%)$ \\
Trend & $90.0 \%$ & $46.3 \%$ & $0.2 \%$ & $0.2 \%$ \\
\hline
\end{tabular}


TABLE 7. Correlation coefficients between summer percentage dry areas in China and oceanic factors at different time scales decomposed by EEMD, along with their $p$ values and effective degrees of freedom.

\begin{tabular}{llrrc}
\hline \hline Time scale & $\begin{array}{c}\text { Correlated oceanic } \\
\text { process }\end{array}$ & \multicolumn{1}{c}{$r$} & dof & $p$ value \\
\hline Decadal & PDO & 0.25 & 20 & 0.27 \\
Multidecadal & PDO & -0.05 & 4 & 0.005 \\
Trend & Global warming & 0.49 & - & - \\
& NPC & 0.57 & 12 & 0.03 \\
\hline
\end{tabular}

corresponding to the NPC pattern, and the PDO indices corresponding to the PDO pattern). The pair of time series tracks each other reasonably well in each chart with a correlation coefficient greater than 0.6 ( $p$ value $<10^{-7}$ ), which corroborates the above attributions of these SVD patterns. The expansion coefficient of NPC mode $\left(W_{2}^{\prime}\right)$ compares better with the NPC SST anomaly than that of the $S_{2}^{\prime}$.

\section{Time-scale analysis of summer drought in China and oceanic factors using EEMD}

The EEMD method was used to decompose percentages of dry areas in the summers of 1901-2012 into various time-scale modes and a nonlinear trend. Here, a pixel of drought in a specific year was defined locally as a case in which the PDSI was smaller than the value of the 20th percentile of the 1901-2012 period (dry area). Similar results were obtained for global drought defined with PDSI $<-2.0$ (dry area II), shown in Table 5 . However, we do not recommend the latter definition because the majority of the drought pixels may be distributed in specific regions where a long-term moisture deficit persists. The present research was concerned with not only extreme drought comparisons across the country but also the relative drying tendency over a long period in specific regions compared to the moisture conditions there. The oceanic factors identified via SVD analysis (including Arctic sea ice loss-global warming, NPC, and PDO, measured respectively by global mean SST anomalies, mean SST anomalies over the NPC and PDO indices) were also decomposed via EEMD (Tables 6-9).

EEMD results shown in Table 5 indicate that summer drought in China has oscillation periods of 3.8 (M1), 12.3 (M2), 19.5 (M3), 41.4 (M4), and 78.2 yr (M5), along with a nonlinear trend. We obtained four major components from these modes: M1 as interannual variability (with a variance contribution of $40.7 \%$ ), sum of M2 and M3 as decadal variability (30.5\%), M4 as multidecadal variability (11\%), and sum of M5 and nonlinear trend as the long-term trend $(17.8 \%)$.

Both sea ice loss-global warming and NPC during the past century have strong nonlinear trends; their longterm components (M5 + nonlinear trend) account for a considerable proportion of total variance, whether in summer $(93.0 \%$ and $62.3 \%)$ or winter $(86.6 \%$ and $60.5 \%$ ) (Tables 6 and 8). Similarly, ENSO may be regarded as an interannual driver, because greater than $80 \%$ of its variance $(89.0 \%$ in summer and $87.1 \%$ in winter) was contributed by M1 and M2, the mean periods of which are shorter than a decade (4.7-9.1 yr in summer and 4.9-7.0 yr in winter). Torrence and Webster (1999) also detected a strong interannual oscillation in the 2-8-yr ENSO band via wavelet analysis. Because interannual variability of the PDO is strongly dependent upon ENSO (Newman et al. 2003), we treated the PDO as a major signal at decadal (M3) and multidecadal scales (M4) after removing interannual modes M1 and M2. A 17-yr periodicity over the North Pacific at decadal scale was reported by Minobe (1999), and the periods of 43.4-64.4 yr in summer and 42.0-62.1 yr in winter identified by EEMD are broadly consistent with the 50-70-yr oscillation found by Qian and Zhou (2014) in the PDO and by Minobe (1997) over the North Pacific. In comparison with the time scales of the dry area in summer over China, we identify ENSO and PDO as the determinants of interannual and decadal-multidecadal variabilities of summer drought in China, respectively.

Comparisons of the components of summer drought and PDO or NPC indices at different time scales are displayed in Fig. 9. The Student's $t$ test showed that these correlations are statistically significant at the $5 \%$ level.

TABLE 8. Mean periods and their variance contributions (in parentheses) of EEMD modes and the nonlinear trend for global mean SST anomalies, mean SST anomalies over NPC, PDO index, and Niño-3.4 in preceding winter (DJF) (1901-2012).

\begin{tabular}{lccrr}
\hline \hline Mode & Global warming & NPC & PDO & ENSO \\
\hline M1 & $3.7 \mathrm{yr}(8.3 \%)$ & $4.6 \mathrm{yr}(23.7 \%)$ & $4.0 \mathrm{yr}(36.2 \%)$ & $4.9 \mathrm{yr}(70.0 \%)$ \\
M2 & $8.23 \mathrm{yr}(2.4 \%)$ & $8.5 \mathrm{yr}(8.3 \%)$ & $9.5 \mathrm{yr}(21.8 \%)$ & $7.0 \mathrm{yr}(17.1 \%)$ \\
M3 & $16.5 \mathrm{yr}(2.3 \%)$ & $15.8 \mathrm{yr}(5.2 \%)$ & $17.9 \mathrm{yr}(10.4 \%)$ & $13.6 \mathrm{yr}(6.0 \%)$ \\
M4 & $35.6 \mathrm{yr}(0.5 \%)$ & $36.8 \mathrm{yr}(2.3 \%)$ & $42.0 \mathrm{yr}(12.2 \%)$ & $33.9 \mathrm{yr}(3.9 \%)$ \\
M5 & $63.8 \mathrm{yr}(0.8 \%)$ & $86.3 \mathrm{yr}(4.2 \%)$ & $62.1 \mathrm{yr}(12.3 \%)$ & $87.4 \mathrm{yr}(1.1 \%)$ \\
Trend & $85.8 \%$ & $56.3 \%$ & $7.0 \%$ & $1.9 \%$ \\
\hline
\end{tabular}


TABLE 9. Correlation coefficients between summer percentage dry areas in China and previous winter oceanic factors at different time scales decomposed by EEMD, along with their $p$ values and effective degrees of freedom.

\begin{tabular}{llccc}
\hline \hline Time scale & $\begin{array}{c}\text { Correlated oceanic } \\
\text { process }\end{array}$ & $r$ & dof & $p$ value \\
\hline Decadal & PDO & 0.38 & 16 & 0.12 \\
Multidecadal & PDO & 0.66 & 6 & 0.007 \\
Trend & Global warming & 0.53 & - & - \\
& NPC & 0.77 & 17 & 0.02 \\
\hline
\end{tabular}

At decadal scale, significant positive correlations between percentage dry area in China and PDO in summer $(0.25 ; p$ value $=0.27)$ or winter $(0.38 ; p$ value $=0.12)$ imply a drying forcing of PDO throughout the year. The multidecadal variability of drought is negatively correlated with PDO in contemporary summer $(-0.05)$ and positively correlated with PDO the previous winter (0.66). The correlations between nonlinear trend of dry area and NPC SST anomalies are relatively high, whether in summer (0.57) or winter (0.77) (Figs. 9e,f). But they do not track very well with each other. This is because the trend of NPC SST anomalies is influenced by global SST anomalies and therefore has an uptrend. Based on the geographic regionalization suggested by Zhao (1983), we calculated the percentage dry areas of eastern China $\left(18^{\circ}-53.5^{\circ} \mathrm{N}, 91.5^{\circ}-122.5^{\circ} \mathrm{E}\right)$, northwestern China $\left(36^{\circ}-50^{\circ} \mathrm{N}, 74^{\circ}-122^{\circ} \mathrm{E}\right)$, and the Tibetan Plateau $\left(27^{\circ}-40^{\circ} \mathrm{N}, 73^{\circ}-104.5^{\circ} \mathrm{E}\right)$ (Fig. 1). Among the three regions, only the dry area of the Tibetan Plateau showed a rise-fall trend like SST over the NPC, adding credibility to NPC's role in drought over that plateau.

\section{Relative influence of oceanic factors on Chinese regional drought using MLR}

When we explore the relative influence of different modes on Chinese regional drought, we assume that ENSO-related interannual variations have little effect on long-term PDSI variability in China and focus on PDO-related, decadal-multidecadal oscillations. MLR was applied to 9-yr running-average PDSI and global SST. Spatial patterns associated with the regression coefficients (Figs. 10a-c,e-g) strongly resemble the heterogeneous correlation patterns of the leading three SVD modes on the 9-yr running-average PDSI and global SST (Figs. 5 and 6). The regression analysis provides more explicit information on regions where each SST mode had the greatest influence (Figs. 10d,h). The sea ice loss-global warming pattern affected Inner Mongolia, northwestern and northeastern China, and the southern part of northern China the most, while the
NPC mode dominated a large part of the Tibetan Plateau and northwest part of northern China. Meanwhile, PDO has major influence in southeastern China and part of the northeastern China, with the signal more significant when the expansion coefficient of winter PDO mode is used than that of the summer PDO mode. The relevant statistics for the MLR analyses are presented in Fig. S3 of the supplemental material. The F test results show that the regression models in most pixels are statistically significant at the $5 \%$ level, with the residual sequence accounted for by the Durbin-Watson test. Variance inflation factor test results indicate predictors are independent in most pixels.

As a demonstration for how each mode affects the variability of the drought in different regions of China, we calculated average PDSI values over northern China (NC-PDSI; $35^{\circ}-42.5^{\circ} \mathrm{N}, 110^{\circ}-117.5^{\circ} \mathrm{E}$ ) (Fig. 1), which is consistent with the study area of $\mathrm{Ma}$ and Shao (2006) and Qian and Zhou (2014), and the Tibetan Plateau [TP-PDSI; $27^{\circ}-40^{\circ} \mathrm{N}, 73^{\circ}-104.5^{\circ} \mathrm{E}$; the geographic regionalization suggested by Zhao (1983)]. NC-PDSI and TP-PDSI are shown in Figs. 11a and 11b, respectively. Since NPC and PDO signal is more obvious in winter than that in summer (Figs. 5 and 6), we only compute the correlations between expansion coefficients of winter modes and PDSI in these regions (Figs. 11c-h). The Student's $t$ test shows all these correlations are statistically significant at the 5\% level. Both a positive correlation between the expansion coefficient of the NPC mode and NC-PDSI $(r=0.41)$ and a negative correlation between the expansion coefficient of the NPC mode and TP-PDSI $(r=-0.62)$ echo the heterogeneous correlation patterns (Figs. 5e and 6e) and regions influenced by the NPC (Figs. 10d,h). The correlation between the expansion coefficient of the PDO mode and NC-PDSI is -0.23 , while its correlation with TP-PDSI is -0.33 .

Based on Fig. 11, we think that both NPC and PDO modes are important to the variability of drought in northern China and the Tibetan Plateau, with the NPC mode more important in the centennial scale while the PDO mode is probably more important in the multidecadal scale. In particular, a sharp turning point appears around year 1960 in both the drought trend of these two regions and the NPC mode. The SVD analyses here enable us to extract and identify the importance of the NPC mode. This is probably an important complement to the finding of Qian and Zhou (2014), who demonstrated the importance of PDO to the variability of drought over northern China. Figure 8c may have explained the secular trend in Fig. 1b of Qian and Zhou (2014). It should be noted, however, that here NC-PDSI counts only the summer values while Qian and Zhou 

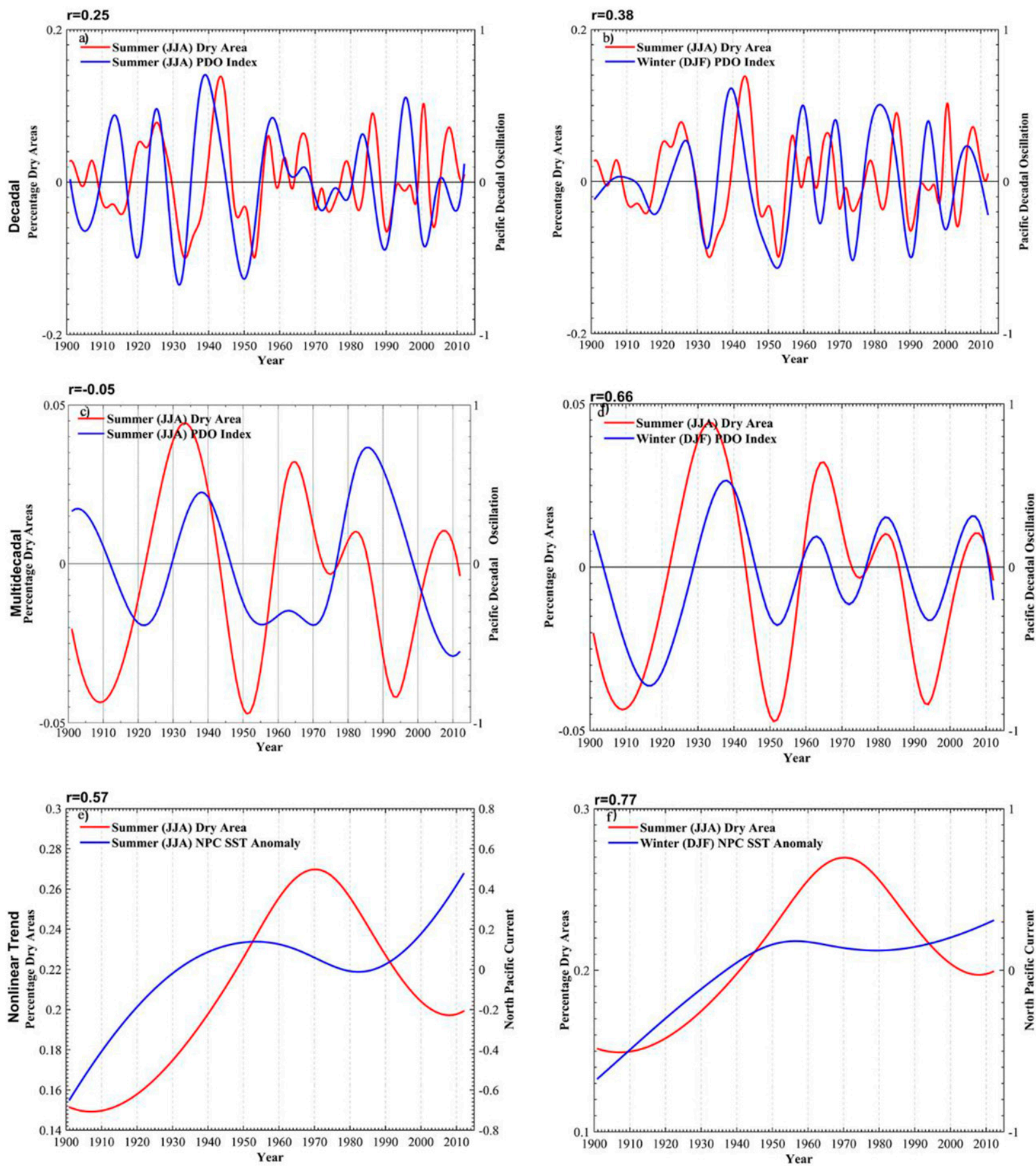

FIG. 9. Components of summer (JJA) percentage of dry areas across China and seasonal PDO indices or SST anomaly over NPC at different time scales (1901-2012). (a) Decadal components of dry area and of summer PDO indices, (b) decadal components of dry area and winter PDO indices, (c) multidecadal components of dry area and summer PDO indices, (d) multidecadal components of dry area and winter PDO indices, (e) nonlinear trends of dry area and summer SST anomaly over NPC, and (f) nonlinear trends of dry area and winter SST anomaly over NPC. Correlation coefficient $r$ between the two components is provided at the top left for each panel. 
a
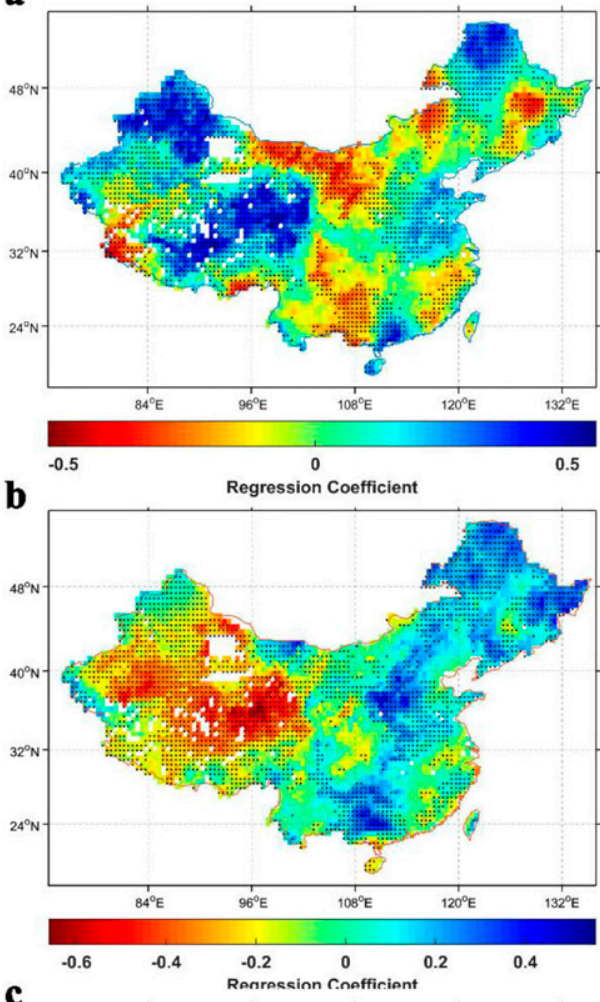

c

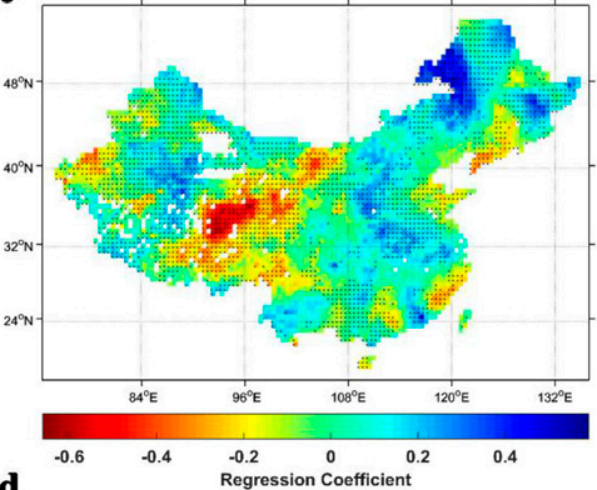

d

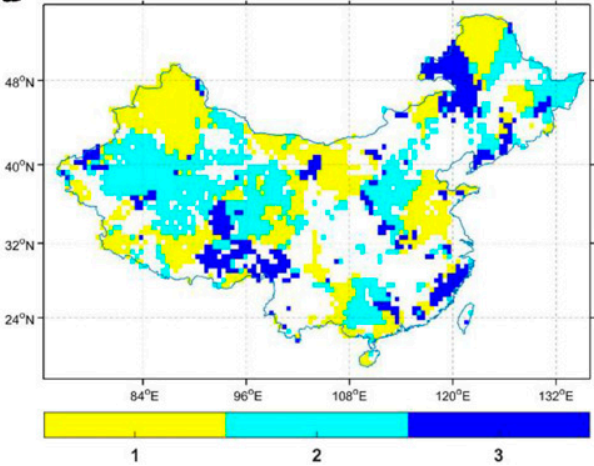

e

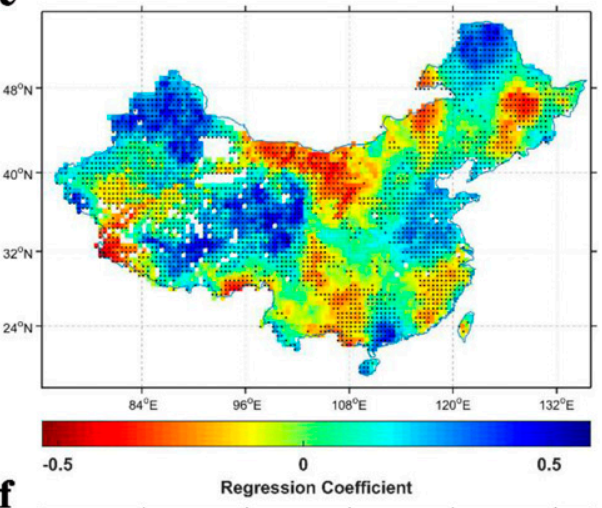

f

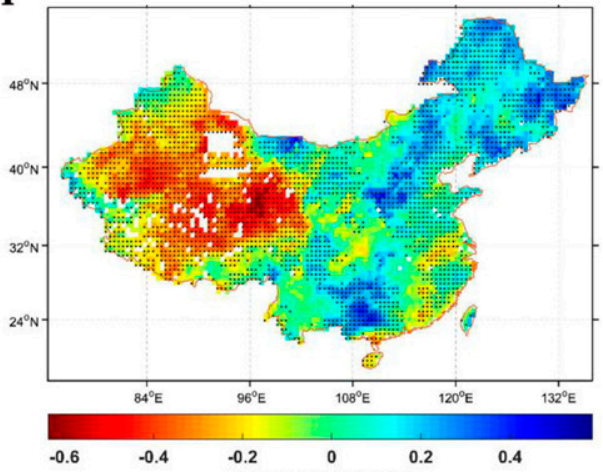

g
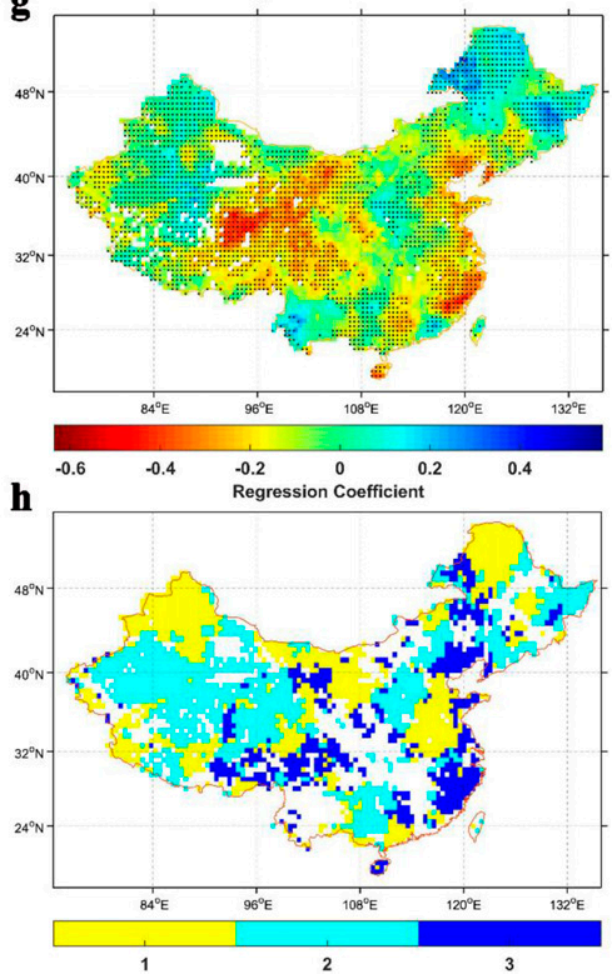

FIG. 10. MLR of low-pass-filtered summer PDSI on expansion coefficients of the leading three SVD patterns for low-pass-filtered global SST in summer or previous winter $\left(S_{1}^{\prime}-S_{3}^{\prime}\right.$ or $\left.W_{1}^{\prime}-W_{3}^{\prime}\right)$. (a) Regression coefficient of $S_{1}^{\prime}$, the sea ice loss-global warming mode; (b) regression coefficient of $S_{2}^{\prime}$, the NPC mode; (c) regression coefficient of $S_{3}^{\prime}$, the PDO mode; and (d) The strongest influential factor at every pixel in summer. Only those pixels significant at 0.05 level are shown. (e) As in (a), but for $W_{1}^{\prime}$; (f) as in (b), but for $W_{2}^{\prime}$; (g) as in (c), but for $W_{3}^{\prime}$; and (h) as in (d), but for winter. In (a)-(c) and (e)-(g), pixels where significance of the coefficient is at 0.05 level are shown with stippling. 
a

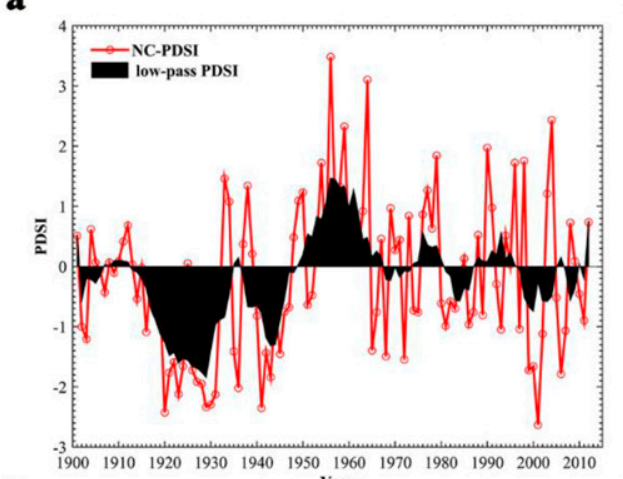

c

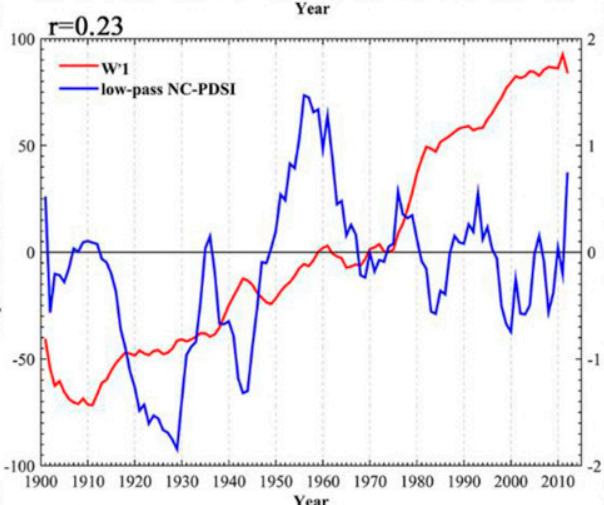

e

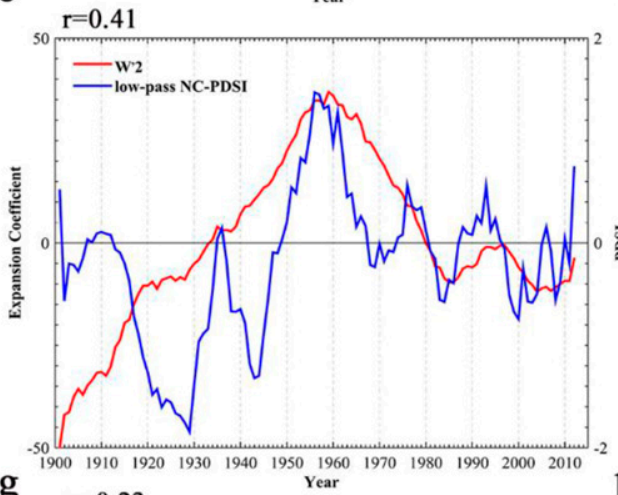

g

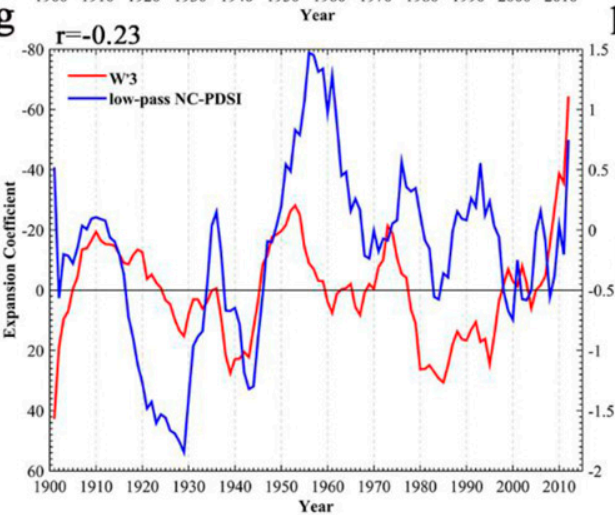

b
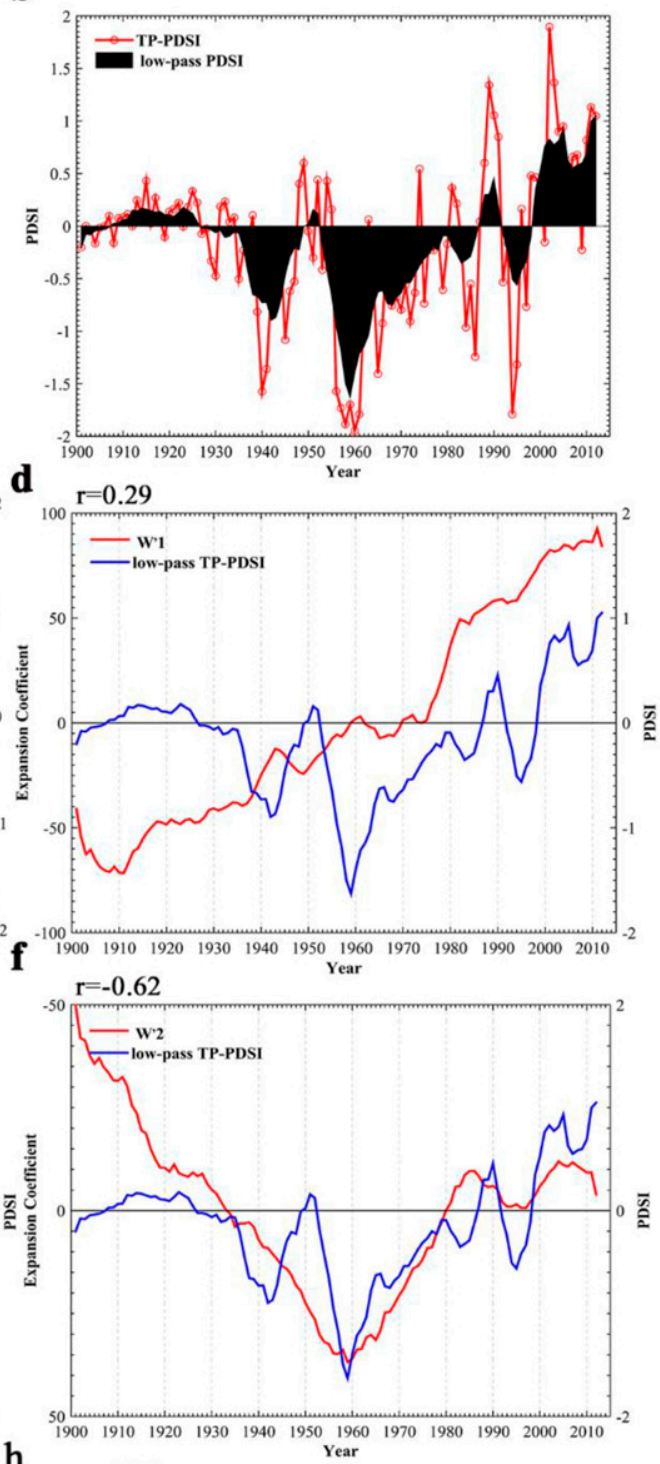

h

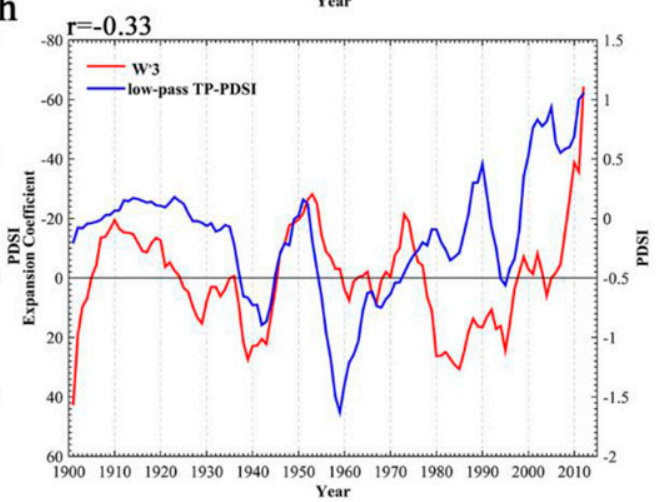

FIG. 11. (a) Summer (JJA) NC-PDSI of 1901-2012 and its 9-yr running mean (shaded). Expansion coefficients for (c) $W_{1}^{\prime}$, (e) $W_{2}^{\prime}$, and (g) $W_{3}^{\prime}$ and low-pass-filtered NC-PDSI. (b),(d),(f),(h) As in (a),(c),(e),(g), but for TP-PDSI. The $y$ axis is reversed for visual purposes in (f)-(h). Correlation coefficient $r$ between the two time series is provided at the top left for each panel. 
(2014) used monthly and annual values, which may be the reason why our Fig. 11a looks different from their Fig. 3.

The influence of sea ice loss-global warming on the evolution of drought in these two regions should not be overlooked either. It has a relatively simple variability compared to the other two modes-an almost linear trend. It is likely that the combined influence of all three modes cause the significant drying trend of the Tibetan Plateau region since the 1960 s.

\section{Summary}

In the present study, we did a spatiotemporal decomposition of summer moisture variability in China and its relationship with seasonal global SST anomalies for the 112-yr period of 1901-2012. We studied SVD patterns of both summer and winter SST to determine the different effects of oceanic forcing on China drought. SST patterns including ENSO, PDO, and NPC, as well as Arctic sea ice loss and global warming, were identified as the dominant factors of summer drought variability. The temporal structures of connections between Chinese drought and those oceanic factors were also analyzed based on the EEMD method. ENSO, PDO, and the combination of NPC and global warming were sorted into drivers of interannual variability, decadal-multidecadal oscillation, and nonlinear trend, respectively. Finally, MLR was used to explore the relative importance of the SST patterns in the summer drought of China.

When the interannual variability is filtered out, the leading three SVD modes, sea ice loss-global warming, NPC, and PDO, collectively explain greater than $88 \%$ of the squared covariance between summer PDSI over China and global SST anomalies (90\% for summer SST and $88 \%$ for winter SST). The sea ice loss-global warming mode alone accounts for over half the squared covariance. It influences Inner Mongolia, northwestern, northeastern China, and the southern part of northern China the most. The NPC mode dominates over northwest part of northern China and the Tibetan Plateau. The PDO plays a major role in southwestern, northern, and southeastern China.

The importance of the NPC mode in the variability of drought in China is probably the major discovery of the current study. From the SST pattern extracted from winter data, this mode is most likely due to the variability of Kuroshio. The NPC mode has a large influence on the centennial-scale variability as has been demonstrated for northern China and the Tibetan Plateau regions. However, further investigation is required in the future to understand the underlying physical mechanisms in more detail.
Acknowledgments. This study was supported by the National Natural Science Foundation of China (Grants 41371096 and 41130534). We thank Shuyao Wu for careful reading of the manuscript and helpful suggestions on the writing. We also thank Ben Tian and Yang Wang from the National Climate Center of the China Meteorological Administration and Lei Fan from Ocean University of China for academic discussion. Constructive comments and helpful suggestions from two anonymous reviewers are greatly appreciated.

\section{REFERENCES}

Ahn, Y. I., and D. K. Lee, 2002: Impact of bogus tropical cyclones on summertime circulation in regional climate simulation. J. Geophys. Res., 107, 4303, doi:10.1029/2001JD000416.

Alcaraz-Segura, D., E. Chuvieco, H. E. Epstein, E. S. Kasischke, and A. Trishchenko, 2010: Debating the greening vs. browning of the North American boreal forest: Differences between satellite datasets. Global Change Biol., 16, 760-770, doi:10.1111/j.1365-2486.2009.01956.x.

Bretherton, C. S., C. Smith, and J. M. Wallace, 1992: An intercomparison of methods for finding coupled patterns in climate data. J. Climate, 5, 541-560, doi:10.1175/ 1520-0442(1992)005<0541:AIOMFF>2.0.CO;2.

_-, M. Widmann, V. Dymnikov, J. Wallace, and I. Bladé, 1999: The effective number of spatial degrees of freedom of a time-varying field. J. Climate, 12, 1990-2009, doi:10.1175/ 1520-0442(1999)012<1990:TENOSD>2.0.CO; 2 .

Butterworth, S., 1930: On the theory of filter amplifiers. Exp. Wireless Wireless Eng., 7, 536-541.

Clow, D. W., 2010: Changes in the timing of snowmelt and streamflow in Colorado: A response to recent warming. J. Climate, 23, 2293-2306, doi:10.1175/2009JCLI2951.1.

Dai, A., 2011a: Drought under global warming: A review. Wiley Interdiscip. Rev.: Climate Change, 2, 45-65, doi:10.1002/wcc.81.

- 2011b: Characteristics and trends in various forms of the Palmer drought severity index during 1900-2008. J. Geophys. Res., 116, D12115, doi:10.1029/2010JD015541.

- 2013: Increasing drought under global warming in observations and models. Nat. Climate Change, 3, 52-58, doi:10.1038/ nclimate1633.

Draper, N. R., H. Smith, and E. Pownell, 1966: Applied Regression Analysis. Wiley, $407 \mathrm{pp}$.

Engle, R. F., 1982: Autoregressive conditional heteroscedasticity with estimates of the variance of United Kingdom inflation. Econometrica, 50, 987-1007, doi:10.2307/1912773.

Fensholt, R., and S. R. Proud, 2012: Evaluation of Earth observation based global long term vegetation trends-Comparing GIMMS and MODIS global NDVI time series. Remote Sens. Environ., 119, 131-147, doi:10.1016/j.rse.2011.12.015.

Folland, C. K., and D. E. Parker, 1995: Correction of instrumental biases in historical sea surface temperature data. Quart. J. Roy. Meteor. Soc., 121, 319-367, doi:10.1002/qj.49712152206.

Fu, C. B., and X. L. Teng, 1988: Relationship between summer climate in China and El Niño/Southern Oscillation phenomenon. Chin. J. Atmos. Sci., 12, 133-141.

Harris, I., P. D. Jones, T. J. Osborn, and D. H. Lister, 2014: Updated high-resolution grids of monthly climatic observations_-The CRU TS3.10 dataset. Int. J. Climatol., 34, 623-642, doi:10.1002/joc.3711. 
Heim, R. R., Jr., 2002: A review of twentieth-century drought indices used in the United States. Bull. Amer. Meteor. Soc., 83, 1149-1165, doi:10.1175/1520-0477(2002)083<1149: AROTDI $>2.3 . \mathrm{CO} ; 2$.

Hoaglin, D. C., F. Mosteller, and J. W. Tukey, 1983: Understanding Robust and Exploratory Data Analysis. Wiley, 447 pp.

Huang, N. E., and Coauthors, 1998: The empirical mode decomposition and the Hilbert spectrum for nonlinear and nonstationary time series analysis. Proc. Roy. Soc. London, 454A, 903-995, doi:10.1098/rspa.1998.0193.

Huang, R. H., and Y. Wu, 1989: The influence of ENSO on the summer climate change in China and its mechanism. $A d v$ Atmos. Sci., 6, 21-32, doi:10.1007/BF02656915.

IPCC, 2007: Climate Change 2007: Impacts, Adaptation and Vulnerability. Cambridge University Press, $987 \mathrm{pp}$.

Ishii, M., A. Shouji, S. Sugimoto, and T. Matsumoto, 2005: Objective analyses of sea-surface temperature and marine meteorological variables for the 20th century using ICOADS and the Kobe collection. Int. J. Climatol., 25, 865-879, doi:10.1002/ joc.1169.

Japan Meteorological Agency, 2006: Characteristics of Global Sea Surface Temperature Analysis Data (COBE-SST) for climate use. JMA Climate System Monthly Rep., Vol. 12, 116 pp.

Li, X., W. Zhou, and Y. D. Chen, 2015: Assessment of regional drought trend and risk over China: A drought climate division perspective. J. Climate, 28, 7025-7037, doi:10.1175/ JCLI-D-14-00403.1.

Lim, Y.-K., and K.-Y. Kim, 2007: ENSO impact on the space-time evolution of the regional Asian summer monsoons. J. Climate, 20, 2397-2415, doi:10.1175/JCLI4120.1.

Liu, Y., Y. Li, S. Li, and S. Motesharrei, 2015: Spatial and temporal patterns of global NDVI trends: Correlations with climate and human factors. Remote Sens., 7, 13 233-13250, doi:10.3390/rs71013233.

Ma, Z., 2007: The interdecadal trend and shift of dry/wet over the central part of North China and their relationship to the $\mathrm{Pa}$ cific decadal oscillation (PDO). Chin. Sci. Bull., 52, 2130-2139, doi:10.1007/s11434-007-0284-z.

_, and L. Shao, 2006: Relationship between dry/wet variation and the Pacific decadal oscillation (PDO) in northern China during the last 100 years (in Chinese). Chin. J. Atmos. Sci., 30, 464-474.

Mantua, N. J., S. R. Hare, Y. Zhang, J. M. Wallace, and R. C. Francis, 1997: A Pacific interdecadal climate oscillation with impacts on salmon production. Bull. Amer. Meteor. Soc., 78, 1069-1079, doi:10.1175/1520-0477(1997)078<1069: APICOW $>2.0 . \mathrm{CO} ; 2$.

Matei, D., N. Keenlyside, M. Latif, and J. Jungclaus, 2008: Subtropical forcing of tropical Pacific climate and decada ENSO modulation. J. Climate, 21, 4691-4709, doi:10.1175/ 2008JCLI2075.1.

Meehl, G. A., and A. Hu, 2006: Megadroughts in the Indian monsoon region and southwest North America and a mechanism for associated multidecadal Pacific sea surface temperature anomalies. J. Climate, 19, 1605-1623, doi:10.1175/JCLI3675.1.

__ _ _ - and C. Tebaldi, 2010: Decadal prediction in the Pacific region. J. Climate, 23, 2959-2973, doi:10.1175/ 2010JCLI3296.1.

_, H. Teng, and J. M. Arblaster, 2014: Climate model simulations of the observed early-2000s hiatus of global warming Nat. Climate Change, 4, 898-902, doi:10.1038/nclimate2357.

Minobe, S., 1997: A 50-70 year climatic oscillation over the North Pacific and North America. Geophys. Res. Lett., 24, 683-686, doi:10.1029/97GL00504.
_ 1999: Resonance in bidecadal and pentadecadal climate oscillations over the North Pacific: Role in climatic regime shifts. Geophys. Res. Lett., 26, 855-858, doi:10.1029/1999GL900119.

Mu, Q., M. Zhao, J. S. Kimball, N. G. McDowell, and S. W. Running, 2013: A remotely sensed global terrestrial drought severity index. Bull. Amer. Meteor. Soc., 94, 83-98, doi:10.1175/BAMS-D-11-00213.1.

Newman, M., G. P. Compo, and M. A. Alexander, 2003: ENSOforced variability of the Pacific decadal oscillation. J. Climate, 16, 3853-3857, doi:10.1175/1520-0442(2003)016<3853: EVOTPD $>2.0 . \mathrm{CO} ; 2$

Obasi, G., 1994: WMO's role in the international decade for natural disaster reduction. Bull. Amer. Meteor. Soc., 75, 1655-1661, doi:10.1175/1520-0477(1994)075<1655:WRITID>2.0.CO;2.

Palmer, W. C., 1965: Meteorological drought. U.S. Department of Commerce Research Paper 45, 65 pp.

Power, S., T. Casey, C. Folland, A. Colman, and V. Mehta, 1999: Inter-decadal modulation of the impact of ENSO on Australia. Climate Dyn., 15, 319-324, doi:10.1007/s003820050284.

Qian, C., and T. Zhou, 2014: Multidecadal variability of north China aridity and its relationship to PDO during 1900-2010. J. Climate, 27, 1210-1222, doi:10.1175/JCLI-D-13-00235.1.

- Z. Wu, C. Fu, and D. Wang, 2011: On changing El Niño: A view from time-varying annual cycle, interannual variability, and mean state. J. Climate, 24, 6486-6500, doi:10.1175/JCLI-D-10-05012.1.

Qiu, J., 2010: China drought highlights future climate threats. $\mathrm{Na}$ ture, 465, 142-143, doi:10.1038/465142a.

Qu, X., G. Huang, and W. Zhou, 2014: Consistent responses of East Asian summer mean rainfall to global warming in CMIP5 simulations. Theor. Appl. Climatol., 117,123-131, doi:10.1007/ s00704-013-0995-9.

Rajagopalan, B., E. Cook, U. Lall, and B. K. Ray, 2000: Spatiotemporal variability of ENSO and SST teleconnections to summer drought over the United States during the twentieth century. J. Climate, 13, 4244-4255, doi:10.1175/ 1520-0442(2000)013<4244:SVOEAS > 2.0.CO;2.

Rayner, N. A., and Coauthors, 2003: Global analyses of sea surface temperature, sea ice, and night marine air temperature since the late nineteenth century. J. Geophys. Res., 108, 1063-1082, doi:10.1029/2002JD002670.

Screen, J. A., 2011: Sudden increase in Antarctic sea ice: Fact or artifact? Geophys. Res. Lett., 38, L13702, doi:10.1029/ 2011GL047553.

— , and I. Simmonds, 2010: Increasing fall-winter energy loss from the Arctic Ocean and its role in Arctic temperature amplification. Geophys. Res. Lett., 37, L16707, doi:10.1029/2010GL044136.

Serreze, M. C., A. P. Barrett, J. C. Stroeve, and D. N. Kindig, 2009: The emergence of surface-based Arctic amplification. Cryosphere, 3, 11-19, doi:10.5194/tc-3-11-2009.

Shabbar, A., and W. Skinner, 2004: Summer drought patterns in Canada and the relationship to global sea surface temperatures. J. Climate, 17, 2866-2880, doi:10.1175/ 1520-0442(2004)017<2866:SDPICA > 2.0.CO;2.

Torrence, C., and P. J. Webster, 1999: Interdecadal changes in the ENSO-monsoon system. J. Climate, 12, 2679-2690, doi:10.1175/1520-0442(1999)012<2679:ICITEM>2.0.CO;2.

Wang, B., R. Wu, and X. Fu, 2000: Pacific-East Asian teleconnection: How does ENSO affect East Asian climate? J. Climate, 13, 1517-1536, doi:10.1175/1520-0442(2000)013<1517: PEATHD $>2.0 . \mathrm{CO} 2$.

Wang, H., and S. He, 2015: The north China/northeastern Asia severe summer drought in 2014. J. Climate, 28, 6667-6681, doi:10.1175/JCLI-D-15-0202.1. 
Wu, Z., and N. E. Huang, 2009: Ensemble empirical mode decomposition: a noise-assisted data analysis method. $A d v$. Adapt. Data Anal., 1, 1-41, doi:10.1142/S1793536909000047.

,-- J. M. Wallace, B. V. Smoliak, and X. Chen, 2011: On the time-varying trend in global-mean surface temperature. Climate Dyn., 37, 759-773, doi:10.1007/s00382-011-1128-8.

Xie, S.-P., K. Hu, J. Hafner, H. Tokinaga, Y. Du, G. Huang, and T. Sampe, 2009: Indian Ocean capacitor effect on Indowestern Pacific climate during the summer following El Niño. J. Climate, 22, 730-747, doi:10.1175/2008JCLI2544.1.

Ying, K., X. Zheng, X. W. Quan, and C. S. Frederiksen, 2013: Predictable signals of seasonal precipitation in the YangtzeHuaihe River valley. Int. J. Climatol., 33, 3002-3015, doi:10.1002/joc.3644.

Yu, S., 2007: Variations in drought over China based on the modified self-calibrating palmer drought severity index. M.S. thesis, Dept. of Meteorology, Chinese Academy of Meteorological Sciences, $67 \mathrm{pp}$.

Zhang, Y., J. M. Wallace, and D. S. Battisti, 1997: ENSO-like interdecadal variability: 1900-93. J. Climate, 10, 1004-1020, doi:10.1175/1520-0442(1997)010<1004:ELIV>2.0.CO;2.

Zhao, P., S. Yang, and R. Yu, 2010: Long-term changes in rainfall over eastern China and large-scale atmospheric circulation associated with recent global warming. J. Climate, 23, 1544 1562, doi:10.1175/2009JCLI2660.1.

Zhao, S., 1983: A new scheme for comprehensive physical regionalization in China (in Chinese). Acta Geogr. Sin., 38, $1-10$.

Zhou, M., and H. Wang, 2014: Late winter sea ice in the Bering Sea: Predictor for maize and rice production in northeast China. J. Appl. Meteor. Climatol., 53, 1183-1192, doi:10.1175/ JAMC-D-13-0242.1. 